\title{
Assimilation of Soil Moisture and Ocean Salinity (SMOS) brightness temperature into a large-scale distributed conceptual hydrological model to improve soil moisture predictions: the Murray-Darling basin in Australia as a test case
}

\author{
Renaud Hostache ${ }^{1}$, Dominik Rains ${ }^{2,3}$, Kaniska Mallick ${ }^{1}$, Marco Chini ${ }^{1}$, Ramona Pelich ${ }^{1}$, Hans Lievens $^{2,4}$, \\ Fabrizio Fenicia ${ }^{5}$, Giovanni Corato ${ }^{1}$, Niko E. C. Verhoest $^{2}$, and Patrick Matgen ${ }^{1}$ \\ ${ }^{1}$ Department Environmental Research and Innovation, Luxembourg Institute of Science and Technology (LIST), \\ Belvaux, Luxembourg \\ ${ }^{2}$ Department of Environment, Ghent University, Ghent, Belgium \\ ${ }^{3}$ Department of Physics and Astronomy, Earth Observation Science, University of Leicester, Leicester, UK \\ ${ }^{4}$ Department of Earth and Environmental Sciences, Katholieke Universiteit Leuven, Heverlee, Belgium \\ ${ }^{5}$ Department of Systems Analysis, Integrated Assessment and Modelling, Swiss Federal Institute of Aquatic Science and \\ Technology (EAWAG), Dübendorf, Switzerland
}

Correspondence: Renaud Hostache (renaud.hostache@list.lu)

Received: 8 August 2019 - Discussion started: 23 August 2019

Revised: 3 July 2020 - Accepted: 17 August 2020 - Published: 12 October 2020

\begin{abstract}
The main objective of this study is to investigate how brightness temperature observations from satellite microwave sensors may help to reduce errors and uncertainties in soil moisture and evapotranspiration simulations with a large-scale conceptual hydro-meteorological model. In addition, this study aims to investigate whether such a conceptual modelling framework, relying on parameter calibration, can reach the performance level of more complex physically based models for soil moisture simulations at a large scale. We use the ERA-Interim publicly available forcing data set and couple the Community Microwave Emission Modelling (CMEM) platform radiative transfer model with a hydro-meteorological model to enable, therefore, soil moisture, evapotranspiration and brightness temperature simulations over the Murray-Darling basin in Australia. The hydrometeorological model is configured using recent developments in the SUPERFLEX framework, which enables tailoring the model structure to the specific needs of the application and to data availability and computational requirements. The hydrological model is first calibrated using only a sample of the Soil Moisture and Ocean Salinity (SMOS) brightness temperature observations (2010-2011). Next, SMOS brightness temperature observations are sequentially assimi-
\end{abstract}

lated into the coupled SUPERFLEX-CMEM model (20102015). For this experiment, a local ensemble transform Kalman filter is used. Our empirical results show that the SUPERFLEX-CMEM modelling chain is capable of predicting soil moisture at a performance level similar to that obtained for the same study area and with a quasi-identical experimental set-up using the Community Land Model (CLM) . This shows that a simple model, when calibrated using globally and freely available Earth observation data, can yield performance levels similar to those of a physically based (uncalibrated) model. The correlation between simulated and in situ observed soil moisture ranges from 0.62 to 0.72 for the surface and root zone soil moisture. The assimilation of SMOS brightness temperature observations into the SUPERFLEX-CMEM modelling chain improves the correlation between predicted and in situ observed surface and root zone soil moisture by 0.03 on average, showing improvements similar to those obtained using the CLM land surface model. Moreover, at the same time the assimilation improves the correlation between predicted and in situ observed monthly evapotranspiration by 0.02 on average. 


\section{Introduction}

Motivated by the impact of climate change on the scarcity or excess of water in many areas around the world, and following the recommendations of the Sendai framework for disaster risk reduction (UNISDR, 2015), several agencies and research institutions have put substantial efforts into better monitoring of and prediction of the hydrologic cycle at a global scale. Such monitoring and prediction efforts are indeed necessary for assessing the risk of extreme hydrological events and for enabling early warning (Revilla-Romero et al., 2016), especially considering that impacts related to such hydrological extremes are expected to increase in the future due to the combined effect of socioeconomic development and climate change (Lehner et al., 2016).

Numerical models, such as hydrological and land surface models, are central in the predicting and forecasting of droughts (Rains et al., 2017) and in helping to better anticipate disasters and the associated emergency responses (Revilla-Romero et al., 2016). However, model simulations suffer from inherent uncertainties (Liu and Gupta, 2007) due to the simplified representation of physical processes and uncertain forcing (García-Pintado et al., 2015; Hostache et al., 2011) and the lack of data for setting them up and controlling them (Pappenberger et al., 2007; Hostache et al., 2015; Wood et al., 2016). To reduce uncertainty in model simulations, an advanced solution that has gained increased interest over the last few decades is the integration of remote sensing data into models (Andreadis and Schumann, 2014; Hostache et al., 2018; De Lannoy and Reichle, 2016b). This approach pursues an optimal combination of hydro-meteorological modelling and remote sensing, for example by using satellite measurements as forcing or calibration data and/or for regular updates of the model states or parameters (Moradkhani, 2007). This allows the periodic controlling and correcting of the models via external observations. In forecasting mode, such data assimilation approaches allow one to keep the predictions on track, while in hind-casting mode they enable improved simulations of measured fluxes and states of the past.

Many advances have been made in these areas of research, and spaceborne sensors are already providing a wealth of Earth observation data with many applications in hydrology (Brocca et al., 2012; De Lannoy and Reichle, 2016b). In particular, satellite surface soil moisture (SM) estimates are available at temporal and spatial resolutions compatible with operational hydrology requirements, especially at the large scale (De Lannoy and Reichle, 2016b). Although the assimilation of in situ data is widely established in operational hydrology (Ercolani and Castelli, 2017), the assimilation of remotely sensed data sets, such as SM, is a more recent development as this source of data has only become available over the last few decades (e.g. Parada and Liang, 2004; De Lannoy et al., 2007; Jia et al., 2009; Matgen et al., 2012; Su et al., 2013b; Chen et al., 2014; Mohanty et al., 2017).
SM is a key variable in hydrological models. In many of them, including Variable Infiltration Capacity (VIC; Liang et al., 1994), Hydrologiska Byråns Vattenbalansavdelning (HBV; Bergström, S., 1976), modèle du Génie Rural à 4 paramètres Journalier (GR4J, Perrin et al., 2003), etc., SM controls the partitioning of water and energy fluxes. Hence, improving its representation within a numerical model has the potential to improve predictions of the key hydrological variables. In this context, SM data derived from various satellite missions, such as ASCAT (e.g. Brocca et al., 2010, 2012; Dharssi et al., 2011; Draper et al., 2011) and AMSR-E (e.g. Reichle et al., 2007; Yang et al., 2007; Draper et al., 2009), have been assimilated into land surface or hydrological models (e.g. Draper et al., 2012; Renzullo et al., 2014).

Since November 2009, the passive Microwave Imaging Radiometer with Aperture Synthesis (MIRAS) onboard the Soil Moisture and Ocean Salinity (SMOS) satellite has been observing the top-of-the-atmosphere brightness temperature (Tb). The MIRAS sensor is sensitive to $1.4 \mathrm{GHz}$ (L-band) emissions and takes multi-angular measurements at vertical and horizontal polarisations (Kerr et al., 2001). The algorithm used for the retrieval of SM values from SMOS Tb is based on numerical modelling (Kerr et al., 2012). In past studies, SM estimates retrieved from SMOS Tb were mostly assimilated into land surface models and sometimes into conceptual hydrological models (Wanders et al., 2014; Lü et al., 2016). However, the land surface model used for the SM retrieval and the model used for the background simulation are often different, for example, in terms of process representation, model structure and model forcing data sets (e.g. air and soil temperature; De Lannoy and Reichle, 2016a). In the event that the background simulation is carried out using a conceptual hydrological model, these differences may be even more important, especially in terms of process representation. This potentially results in inconsistencies in the way SM is simulated by the model and retrieved from the observation. Moreover, De Lannoy and Reichle (2016b) argued that this issue can lead to correlations between retrieved and simulated SM errors that cannot be easily handled by data assimilation filters. As a consequence, recent studies (e.g. De Lannoy and Reichle, 2016a; Lievens et al., 2016; Rains et al., 2017, 2018; Muñoz-Sabater et al., 2019) have aimed to directly assimilate SMOS Tb into such land surface models. To do so, these studies used a radiative transfer model (e.g. the Community Microwave Emission Modelling platform-CMEM; de Rosnay et al., 2009) as the observation operator of the assimilation filter, allowing one to derive $\mathrm{Tb}$ from SM simulations. In this context, De Lannoy and Reichle (2016a) showed that assimilating either SM retrievals or observed $\mathrm{Tb}$ yields almost the same correlation level between in situ observed and simulated SM (average correlation equals 0.6 based on the records obtained from many measurement sites distributed across the United States of America), and Lievens et al. (2016) showed that the assimilation of SM retrievals slightly outperforms the assimilation of observed $\mathrm{Tb}$. 
Currently, for applications at a large scale, there is a tendency to rely on more complex physically based hydrological models in order to better capture the hydrological processes at hand (Devia et al., 2015). However, this may sometimes be detrimental to large-scale operational hydrology, due to the increased computational demand and the potential unavailability of the required data sets for parameter estimation. Faster models are key tools for carrying out simulations at a large scale without requiring a high computational demand. Faster models are therefore powerful for near-real-time forecasting applications and when large ensemble of model runs are required. In this context, conceptual models that allow for more efficient and rapid simulations offer an alternative to more physically based land surface models (Devia et al., 2015; El Hassan et al., 2013). The main argument against the use of a conceptual model is often the need for site-specific parameter calibration that is often infeasible in data-scarce areas. However, with the recent increase in satellite missions providing global observations of key hydrological variables at high temporal and spatial resolutions, it becomes possible to envisage the calibration of conceptual models - even at a large scale. Hence, a science question that is worth investigating is whether a flexible conceptual model, relying on parameter calibration, can reach the performance level of a more complex physically based model for soil moisture simulations at large scales.

The SUPERFLEX modelling framework (Fenicia et al., 2016) enables the tailoring of the model structure (i.e. adapting the model architecture via reorganising the constituting reservoirs) for the specific needs of the application. In particular, here we seek a simplified representation of the main controlling processes and computational efficiency in order to perform rapid simulations over large areas and for long periods. Compared to more physically based land surface models, the model built with SUPERFLEX offers fast running simulations without the need for high-performance computing facilities, and it allows one to adapt the model's spatial resolution and soil stratification to the characteristics of the satellite data sets that are to be assimilated.

Following the study by Rains et al. (2017), we evaluate here the potential of SMOS $\mathrm{Tb}$ assimilation for improving SM simulations of this distributed conceptual hydrological model. The general objective of this study is to assess the performance of a soil moisture prediction chain based on the assimilation of SMOS Tb into a coupled SUPERFLEXCMEM model. Moreover, we propose comparing it to the one developed in Rains et al. (2017), based on the Community Land Model (CLM; Oleson et al., 2013). To enable a fair and meaningful evaluation and comparison, we use a quasi-identical experimental set-up to the one of Rains et al. (2017), except that we use the SUPERFLEX instead of the CLM model here to simulate soil moisture. As a test case, we use the Murray-Darling basin in Australia, and we simulate the distributed time series of soil moisture over the period 2010-2015.
The specific objectives of this study are as follows: (i) to compare the SUPERFLEX and CLM models in their ability to simulate $\mathrm{Tb}$ and soil moisture, and (ii) to evaluate the improvement in model predictions when assimilating SMOS Tb observations. It is worth mentioning that, here and in the remainder of the paper, the term simulated $\mathrm{Tb}$ is used to name $\mathrm{Tb}$ that is derived from the simulated soil moisture using the radiative transfer model parameterised to emulate SMOS observations. The simulated $\mathrm{Tb}$ is therefore meant to emulate SMOS observation based on simulated soil moisture. As an additional objective, we also propose evaluating how the assimilation of SMOS Tb can help to improve evapotranspiration predictions.

In the next sections, we first present the database used for the experiment, the coupling between the hydrological (SUPERFLEX) and the radiative transfer (CMEM) models and the data assimilation experiment. Next, we calibrate the hydrological model using SMOS Tb observations, we evaluate the forward run of the SUPERFLEX-CMEM prediction chain and we compare the performances with the ones obtained in Rains et al. (2017). Then, we assess and discuss the results of the assimilation experiment, using the study by Rains et al. (2017) as a benchmark. As a further discussion element, we finally evaluate the impact of the assimilation of SMOS $\mathrm{Tb}$ on evapotranspiration simulations.

\section{Material and method}

\subsection{Study area and available data}

\subsubsection{Study area}

The study area is the Murray-Darling basin (MDB) in southeastern Australia. The three main rivers of the MDB, namely the rivers Darling, Murray and Murrumbidgee are among the longest rivers in Australia. The MDB covers an area of $1.06 \times 10^{6} \mathrm{~km}^{2}$, representing approximately $14 \%$ of the land surface of Australia. Due to its large dimensions, the basin exhibits various climate regimes, from subtropical in the north and semi-arid in the west to mostly temperate in the south. The average interannual rainfall ranges from up to $1500 \mathrm{~mm}$ in the eastern side to less than $300 \mathrm{~mm}$ in the western side of the MDB (MDBA, 2018). The average interannual temperature ranges between ca. $10^{\circ} \mathrm{C}$ in southeastern side and ca. $20^{\circ} \mathrm{C}$ in western side of the MDB (MDBA, 2018).

\subsubsection{Meteorological forcings}

Time series of rainfall and $2 \mathrm{~m}$ air and soil temperature predictions are globally available at a $3 \mathrm{~h}$ time step and $0.25^{\circ}$ spatial resolution (downscaling from the original $0.75^{\circ}$ spatial resolution) from the ERA-Interim reanalysis data set (Dee et al., 2011). It would have been possible to use the more recent and accurate ERA5 data set as well, but we de- 


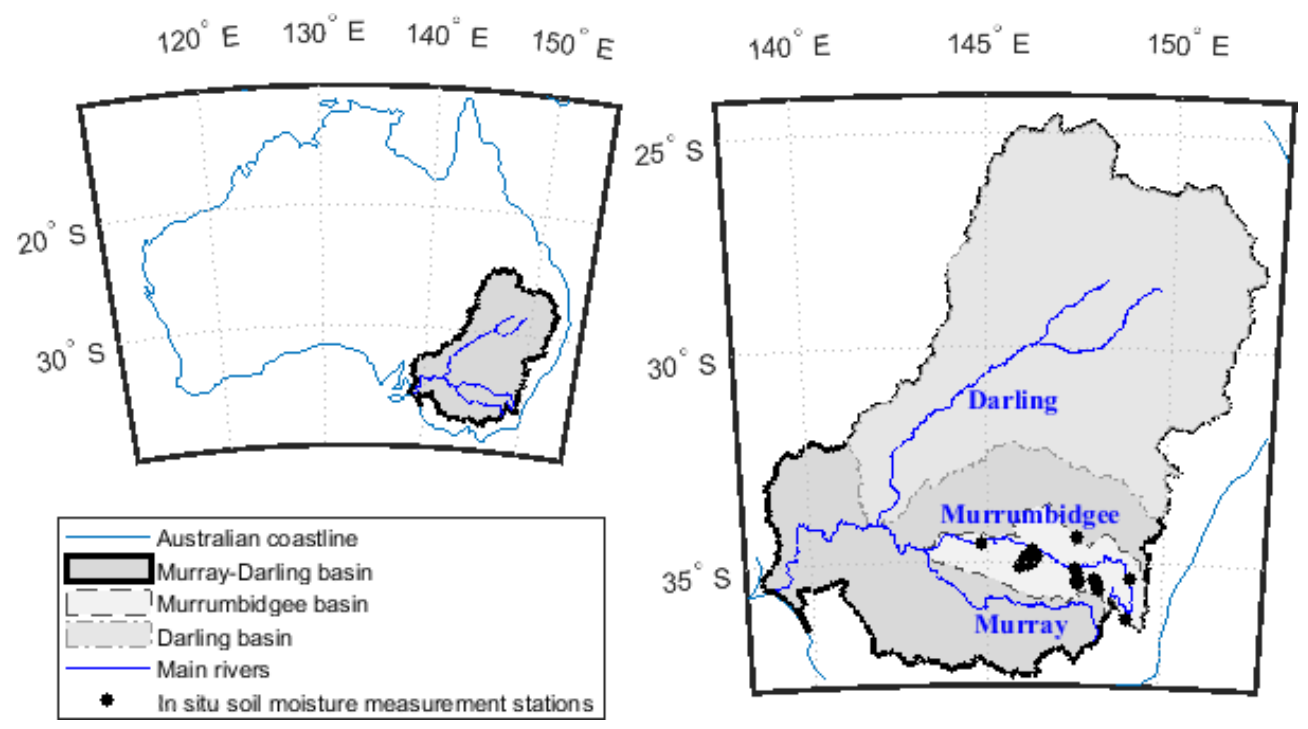

Figure 1. Study area: the Murray-Darling, Murray, Darling and Murrumbidgee basins, river stream courses and in situ soil moisture measurement locations.

cided here to use ERA-Interim as it was also used in Rains et al. (2017). From this data set, for each grid cell lying within the limits of the MDB, we extracted rainfall and soil and $2 \mathrm{~m}$ air temperature for the period 2009-2016. Soil temperature was extracted for the two upper soil layers, having depths of 7 and $21 \mathrm{~cm}$ respectively. Next, the resulting time series were uniformly redistributed to an hourly time step. For the accumulated variable (i.e. rainfall), the predicted amount was redistributed uniformly from a $6 \mathrm{~h}$ accumulation to a $1 \mathrm{~h}$ accumulation in order to keep water balance. For the other variables (i.e. air and soil temperature), the value was imposed to be constant over $6 \mathrm{~h}$ and equal to the ERA-Interim predicted value. The potential evapotranspiration (Ep) was estimated from the air temperature data using the Hamon formula (Hamon, 1963). Rainfall and Ep time series are used as inputs of the SUPERFLEX hydrological model (see Sect. 2.2.1). Soil and air temperature time series are used as inputs of the CMEM radiative transfer models (see Sect. 2.2.2)

\subsubsection{SMOS Tb observations}

The SMOS database used in this study is identical to the one used in the study by Rains et al. (2017). It covers the period 2010-2015 and consists of SMOS Level 3 daily Tb at a horizontal polarisation and $42.5^{\circ}$ incidence angle. The data are provided by the Centre Aval de Traitement des Données SMOS (CATDS; version 310). SMOS acquisitions with probabilities of radio frequency interference (RFI) greater than 0.2 , a data quality index higher than 0.07 or activated science flags, namely strong topography, snow, flooding, urban areas, coastal zone and precipitation were filtered out from the initial database. The filtered observation data were resampled from the Equal-Area Scalable Earth Grid 2 (EASE2) $25 \mathrm{~km}$ grid to a $0.25^{\circ}$ model grid aligned with that of the ERA-Interim data set by using inverse distance interpolation.

\subsubsection{In situ soil moisture observations}

As an independent data set for evaluating the model results, we make use of in situ soil moisture measurements from the OzNet and CosmOz measurement networks (Smith et al., 2012). These data sets provide time series of soil moisture acquired using, respectively, time domain reflectometry (TDR) probes and cosmic-ray neutron probes. Depending on the type of probe, soil moisture observations are available for various soil depths, namely $5,8,30,60$ and $90 \mathrm{~cm}$. The measurement stations are mainly located within the Murrumbidgee catchment as the latter was selected as one of the sites for SMOS calibration and validation campaigns (Peischl et al., 2012; Holgate et al., 2016; Su et al., 2013a). More details on the measurement techniques and the measurement network can be also found in other studies of Australia and the MDB (e.g. Holgate et al., 2016; Su et al., 2013a). It is worth mentioning that the in situ soil moisture data set is provided with local or limited measurement footprints (a few hundreds of square metres at maximum), whereas the hydrological model simulates average soil moisture over much larger areas (a few hundreds of square kilometres). As a consequence, the comparison between the model results and in situ observations necessarily suffers from scale representativeness issues. 


\subsubsection{In situ flux tower measurements}

As an additional independent data set for evaluating the model results, we also make use of in situ flux tower measurements from the TERN OzFlux measurement network (http://www.ozflux.org.au/, last access: 1 August 2019). This data set provides, among other variables, a time series of latent heat fluxes that were converted into actual evapotranspiration rates using the latent heat of vaporisation constant. The measurement stations are mainly located in the southern part of the MDB. Moreover, the in situ evaporation data, just like the previously described soil moisture data, are provided with local or limited measurement footprints.

\subsection{The soil moisture and $\mathrm{Tb}$ prediction chain}

\subsubsection{The conceptual hydrological model}

The SUPERFLEX modelling framework (hereafter denoted as SFX; Fenicia et al., 2011, 2016) is used to build the hydrological model. This modelling framework was developed with the aim to facilitate model development and allow model structure comparisons. The modelling platform is based on generic building components that can be configured and combined in various ways to generate different model architectures. Hydrologists can therefore hypothesise, build and test different model structures. For example, it allows adaptation of the model structure to the forcing and observation data sets (e.g. in terms of spatial and vertical resolutions) and specific characteristics of the catchment. In the context of this study, we take advantage of this flexibility and define the model architecture in such a way that it allows us to easily ingest globally available meteorological forcing data and, at the same time, integrate Tb as observed by the SMOS satellite. The model is therefore distributed over grid cells of $0.25^{\circ}$ aligned on the grid used in the ERA-Interim data set, and simulations are carried out at an hourly time step.

The architecture of the developed model is represented in Fig. 2 for one model grid cell. It is mainly composed of two stratified upper root zone layers represented by two reservoirs, namely UR $u$ and URl. The grey box in Fig. 2 also identifies the deeper reservoirs and the routing function that simulates subsurface and surface runoff based on deeper soil layer water storage. In SFX, the deeper reservoirs are typically two interconnected fast and slow reservoirs with associated lag functions whose outflows are summed up to compute the surface runoff (Fenicia et al., 2016). In this study, since we focus on the two upper root zone layers that are of interest for the simulation of soil moisture, the deeper reservoirs and the routing function are switched off and not further referred to in the remainder. It is worth mentioning that the removal of the deeper reservoirs of SFX has no effect on the soil moisture simulations as in SFX there is no upward water circulation from the deeper reservoirs to the upper ones. As a matter of fact, when deeper reservoirs are switched off, wa- ter exits root zone soil layers based on the usual percolation and/or subsurface flow equations (e.g. Eq. 1). The soil moisture simulations within both root zone reservoirs are therefore not impacted.

The upper reservoir (UR $u$ ) is fed by precipitation and loses water through evapotranspiration to the atmosphere and percolation to the second reservoir (UR $l$ ). The latter is then fed by the incoming percolation from the first reservoir and loses water through evapotranspiration to the atmosphere and percolation to deeper soil. Outflow $Q$ from the two root zone layers is estimated based on the simulated storage $S$ and the incoming water amount, using a power function with exponent $\alpha$ as follows:

$Q_{\mathrm{UR} x, i}(t)=P_{\mathrm{UR} x, i}(t) \times\left(\frac{S_{\mathrm{UR} x, i}(t)}{\operatorname{Smax}_{\mathrm{UR} x, i}}\right)^{\alpha_{\mathrm{UR} x, i}}$,

where $t$ is time, $i$ represents the model grid cell number, $x$ stands for upper $(u)$ or lower $(l)$ reservoir, $P_{\mathrm{UR} x, i}$ is the input to the reservoir (precipitation for the upper reservoir and outflow from the upper reservoir for the lower reservoir) and Smax is a parameter representing maximum storage capacity.

The actual evapotranspiration ( $E a$ ) from the two soil layers is estimated based on the simulated storage within the considered reservoir and the potential evapotranspiration $(E p)$, using a power function with exponent $\beta$ as follows:

$$
E a_{\mathrm{UR} x, i}(t)=E p_{i}(t) \times\left(\frac{S_{\mathrm{UR} x, i}(t)}{\operatorname{Smax}_{\mathrm{UR} u, i}+\operatorname{Smax}_{\mathrm{UR} l, i}}\right)^{\beta_{\mathrm{UR} x, i}} .
$$

The variation of storage within the two reservoirs is estimated by solving the water balance equation as follows:

$$
\frac{\mathrm{d} S_{\mathrm{UR} x, i}(t)}{\mathrm{d} t}=P_{\mathrm{UR} x, i}(t)-Q_{\mathrm{UR} x, i}(t)-E a_{\mathrm{UR} x, i}(t) .
$$

For each reservoir, the soil moisture is derived from the storage according to the following:

$\theta_{\mathrm{UR} x, i}(t)=C_{\mathrm{EF} x, i} \frac{S_{\mathrm{UR} x, i}(t)}{\operatorname{Smax} \mathrm{UR} x, i}$,

where $\theta$ is the predicted soil moisture, and $C_{\mathrm{EF}}$ is a so-called effective field capacity.

In the model architecture, the two root zone reservoirs are meant to conceptually represent two stratified soil layers, allowing us to simulate soil moisture over different soil depths. To maintain constant depths of these two layers over the model domain (namely 7 and $21 \mathrm{~cm}$ in accordance with the depth of the two upper soil layers depicted in the ERAInterim data set) the respective reservoir maximum capacities are computed depending on the $C_{\mathrm{EF}}$, considering that the maximum storage capacity of a soil layer can be derived from the $C_{\mathrm{EF}}$ and the soil layer depth $d$ according to the following:

$\operatorname{Smax}_{\mathrm{UR} x, i}=C_{\mathrm{EF} x, i} \times d_{\mathrm{EF} x}$. 


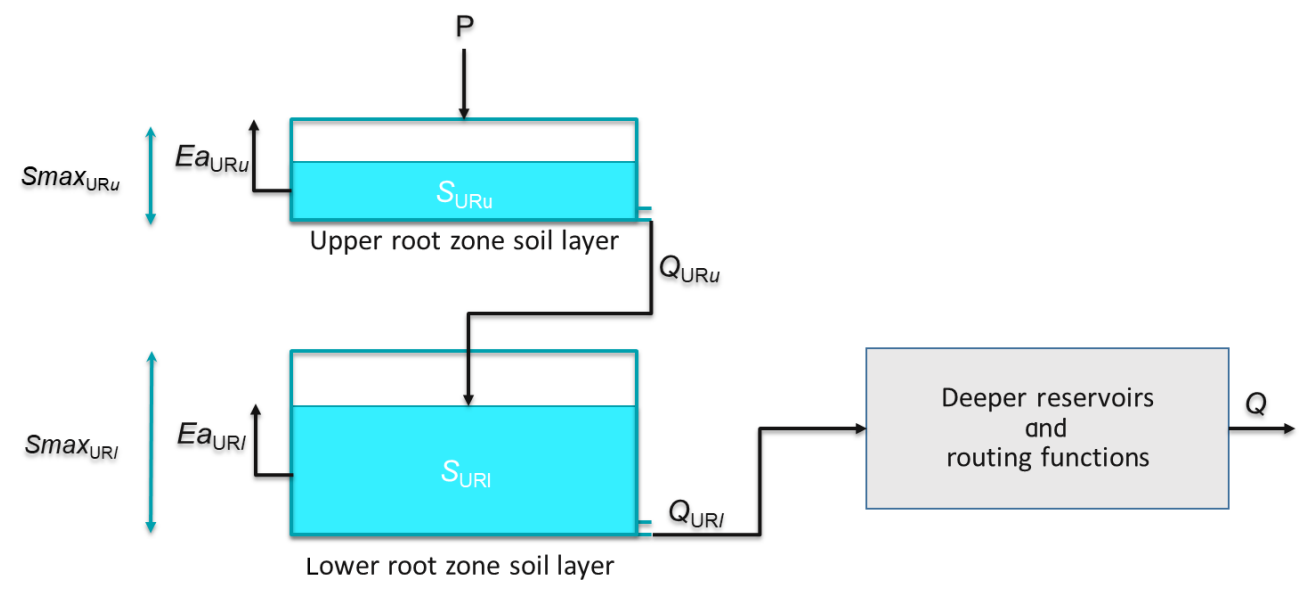

Figure 2. SUPERFLEX (SFX) model architecture.

It is worth noting here that the model structure presented before is replicated on each model grid cell $i$. As a matter of fact, the distributed SFX implemented in this study does not simulate lateral flows within the root zone soil layers. As a consequence, for each grid cell, the model has six calibration parameters, namely $C_{\mathrm{EF} u, i}, \alpha_{\mathrm{UR} u, i}, \beta_{\mathrm{UR} u, i}, C_{\mathrm{EF} l, i}$, $\alpha_{\mathrm{UR} l, i}$ and $\beta_{\mathrm{UR} l, i}$. Moreover, the maximum storage capacities $\operatorname{Smax}_{\mathrm{UR} x, i}$ are computed based on fixed soil layer depths $d_{\mathrm{EF} x}$ and calibrated effective field capacities $C_{\mathrm{EF} u, i}$.

From the SFX model description, it appears that this conceptual model is much simpler than CLM, in particular for the following reasons:

- CLM estimates latent heat fluxes between soil and atmosphere based on aerodynamic diffusion equation and the Monin-Obukhov similarity theory (Oleson et al., 2013), and by taking into account much information such as soil and vegetation type, surface roughness, atmospheric stability and the vegetation coverage, whereas SFX lumps the energy balance contribution to the water balance via a simpler potential evapotranspiration formula, namely the Hamon formula.

- In this study, SFX is structured with two soil layers (respectively $0-7 \mathrm{~cm}$ and $7-21 \mathrm{~cm}$ ), whereas CLM considers five layers for the same soil depth range.

- The set-up of CLM therefore requires much more input data (e.g. soil types and land use), and SFX has a limited number of parameters (six parameters per cell) compared to CLM (potentially tens of parameters per cell, Hou et al., 2012).

It is worth noting here that this list is not exhaustive, and that many other processes are further simplified in SFX compared to CLM. A detailed presentation of CLM is available in Oleson et al. (2013). Table 1 reports the main processes represented in our implementation of SFX and in the CLM set-up of (Rains et al., 2017).

\subsubsection{The radiative transfer model}

To simulate $\mathrm{Tb}$ using soil moisture predictions of the SFX hydrological model, we use the Community Microwave Emission Model version 5.1 (CMEM; de Rosnay et al., 2009). The parameterisation of CMEM and most of the forcings (except SM and soil temperature) are identical to the ones used in the study of Rains et al. (2017), in order to enable a meaningful comparison between both experiments. In particular, the time invariant input data (i.e. soil sand and clay fractions, permanent water surface fractions, ground elevation and vegetation cover types) and the equations used to run CMEM are exactly the same. The ECOCLIMAP vegetation classes (Champeaux et al., 2005) are used to provide CMEM with the plant functional types. The development cycle of vegetation classes is defined in CMEM based on the leaf area index (LAI; Rains et al., 2017). LAI is interpolated at a daily scale from a monthly data set for low vegetation, and a constant LAI value is fixed for high vegetation. The dielectric constant computation is carried out using the Mironov model (Mironov et al., 2004), and the required effective temperature is computed via the Wigneron model (Wigneron et al., 2001). The Fresnel, Choudhury (Choudhury et al., 1979) and Wigneron (Wigneron et al., 2007) models are used to assess smooth surface emissivity, soil roughness and vegetation opacity, respectively. Atmospheric contributions are estimated via the Pellarin method (Pellarin et al., 2003). However, the soil layer depths in CMEM are identical to the ones used in the SFX model, and the soil moisture simulated by SFX is used as an input of CMEM. Moreover, as SFX does not integrate energy balance processes (while CLM does), the soil temperature in our experiment is derived from the ERA-Interim data set.

\subsubsection{Model calibration}

On each grid cell, the SFX model has six calibration parameters (see Sect. 2.2.1). To carry out the calibration, Monte 
Table 1. Main processes implemented in the CLM- and SFX-based studies.

\begin{tabular}{lcc}
\hline Main processes & CLM & SFX \\
\hline Radiative fluxes & Solar and long-wave radiations & Lumped evapotranspiration (Hamon formula) \\
\hline $\begin{array}{l}\text { Evaporation and } \\
\text { transpiration }\end{array}$ & Ground latent heat flux & \\
\cline { 2 - 3 } Subsurface vertical flow & Vegetation latent heat flux & \\
\hline Subsurface lateral flow & Across 10 soil layers (adapted Richards equation) & Across two soil layers (power law dynamics) \\
\hline
\end{tabular}

Carlo simulations, using Latin hypercube sampling within plausible parameter ranges, are carried out. To do so, parameter sets are first randomly generated within such plausible parameter ranges. Next, a SFX-CMEM simulation is carried out for each individual parameter set, and the simulated $\mathrm{Tb}$ is compared, at the grid cell scale, to the values derived from SMOS observations. Eventually, for each individual model grid cell, the parameter set yielding the lowest unbiased root mean square deviation (ubRMSD; Entekhabi et al., 2010, see Eq. 6) while comparing simulated and SMOS-derived $\mathrm{Tb}$ is selected as optimal. The ubRMSD is chosen here has it allows one to remove the bias between simulated and observed soil moisture (and $\mathrm{Tb}$ ) which is common in brightness temperature assimilation studies.

$\mathrm{ubRMSD}=\sqrt{\left\langle\left(\left(y^{\mathrm{s}}(t)-\left\langle y^{\mathrm{s}}\right\rangle_{t}\right)-\left(y^{\mathrm{o}}(t)-\left\langle y^{\mathrm{o}}\right\rangle_{t}\right)\right)^{2}\right\rangle_{t}}$,

where $y^{\mathrm{s}}$ is the simulated $\mathrm{Tb}$ and $y^{\mathrm{o}}$ the observed one, and $\langle.\rangle_{t}$ indicates the average over time. The parameters of the CMEM model were not adjusted, and their default values were used to keep the current experiment quasi-identical to the one of Rains et al. (2017).

\subsection{Data assimilation}

\subsubsection{Data assimilation filter}

In this section, we present the method used to assimilate SMOS Tb into the SFX-CMEM coupled models. The method proposed in this study uses a local ensemble transform Kalman filter (LETKF) introduced by Hunt et al. (2007) and implemented by Miyoshi and Yamane (2007) as the assimilation filter. As usual in ensemble Kalman filtering, the uncertainty in model predictions is represented via a set of $k$ stochastic model realisations ( $k=32$ in this experiment) with different perturbed forcings and/or parameters, while the model and observation errors are assumed to be normally distributed. The localisation is set up so that the assimilation is carried out at the model grid scale. The observation operator is linearly approximated during the analysis step in the LETKF (see Eq. 18 in Hunt et al., 2007). As argued in Hunt et al. (2007), LETKF is deterministic as no additional random error is added to the observation. Let us denote our non- linear model $\mathcal{M}$, namely SFX, that propagates state variables in time (including soil moisture $\theta$ ) between two assimilation time steps (Eq. 7) in the following:

$x_{n, j}^{\mathrm{b}}=\mathcal{M}\left(x_{n-1, j}^{\mathrm{a}}\right)$,

where $x_{n, j}^{\mathrm{b}}$ is the background at time $t_{n}$ when the assimilation is supposed to be carried out for ensemble member number $j$, and $x_{n-1, j}^{\mathrm{a}}$ is the analysis computed at time $t_{n-1}$, i.e. the previous assimilation time step.

The step prior to the assimilation is to run the hydrological model between $t_{n-1}$ and $t_{n}$ to yield the background ensemble. In our study, the application of the LETKF proposed by Hunt et al. (2007) consists of the seven main steps listed hereafter (please note that the temporal index $n$ is not repeated later on for the sake of conciseness).

1. Apply the observation operator, namely CMEM, to the model background ensemble to form the observational background ensemble $y^{\mathrm{b}}=\left[y_{1}^{\mathrm{b}}, \ldots, y_{k}^{\mathrm{b}}\right]$.

2. Compute the ensemble observational background perturbations, based on the ensemble mean $\overline{y^{b}}$, as follows:

$$
\mathbf{Y}^{\mathrm{b}}=\left[y_{1}^{\mathrm{b}}-\overline{y^{\mathrm{b}}}, \ldots, y_{k}^{\mathrm{b}}-\overline{y^{\mathrm{b}}}\right] \text {. }
$$

3. Compute the ensemble background perturbations, based on ensemble mean $\overline{x^{b}}$, as follows:

$$
\mathbf{X}^{\mathrm{b}}=\left[x_{1}^{\mathrm{b}}-\overline{x^{\mathrm{b}}}, \ldots, x_{k}^{\mathrm{b}}-\overline{x^{\mathrm{b}}}\right] .
$$

4. Compute the matrix $\tilde{\mathbf{P}}^{a}=$ $\left[(k-1) \mathbf{I}+\left(\mathbf{Y}^{\mathrm{b}}\right)^{T} \mathbf{R}^{-1} \mathbf{Y}^{\mathrm{b}}\right]^{-1}$, where $\mathbf{I}$ is the identity matrix and $\mathbf{R}$ the observation error covariance matrix.

5. Compute the matrix $\mathbf{W}^{\mathrm{a}}=\left[(k-1) \tilde{\mathbf{P}}^{\mathrm{a}}\right]^{1 / 2}$.

6. Compute the $k$-dimensional vector $\bar{w}^{\mathrm{a}}=$ $\tilde{\mathbf{P}}^{\mathrm{a}}\left(\mathbf{Y}^{\mathrm{b}}\right)^{T} \mathbf{R}^{-1}\left(y^{\mathrm{o}}-\bar{y}^{\mathrm{b}}\right)$, and derive $w_{j}^{\mathrm{a}}$ by adding $\bar{w}^{\mathrm{a}}$ to each column of $\mathbf{W}^{\mathrm{a}}$.

7. Compute the individual member analysis $x_{j}^{\mathrm{a}}=\bar{x}^{\mathrm{b}}+$ $\mathbf{X}^{\mathrm{b}} \mathbf{w}_{j}^{\mathrm{a}}$. 
This process is repeated for each cell of the model domain where a SMOS observation is available at time step $t_{n}$. Once the analysis has been carried out, state variables, namely the storage in the two soil layers of SFX (Sect. 2.3.1), are updated, and the simulation is resumed until the next assimilation time step.

As mentioned in many studies dealing with the assimilation of satellite SM or Tb (e.g. Al Bitar et al., 2012; Matgen et al., 2012; Rains et al., 2017; Al-Yaari et al., 2017), bias removal prior to the assimilation is often a necessary step. In our study, we reduce the bias between simulations and observations by deriving model and observation anomalies, following an identical approach to the one described in Rains et al. (2017). Anomalies are defined as the difference between the original $\mathrm{Tb}$ time series and their interannual climatologies (time-averaged SMOS observation acquired in a $20 \mathrm{~d}$ sliding window centred on the considered day of year). The climatology is computed by, first, smoothing the Tb time series using a $20 \mathrm{~d}$ moving average and, next, computing the interannual average of the smoothed signal. The model background used in the assimilation filter is the simulated $\mathrm{Tb}$ anomaly computed as the difference between the simulated $\mathrm{Tb}$ and its climatology, computed as the climatology of the ensemble mean of the open loop run. The data assimilation is therefore carried out based on the simulated and observed $\mathrm{Tb}$ anomalies.

\subsubsection{Ensemble generation}

To generate an ensemble of simulated $\mathrm{Tb}$, the meteorological forcings of the SFX-CMEM models derived from the ERA-Interim data set, namely the rainfall and the air and soil temperature time series, are randomly perturbed. As in Rains et al. (2017), the perturbation applied to rainfall time series is multiplicative and randomly generated from a log-normal statistical distribution of mean 0 and standard deviation 0.5 . The air temperature time series are perturbed using an additive Gaussian random noise of mean $0 \mathrm{~K}$ and standard deviation $2.5 \mathrm{~K}$. Each time step and each model grid cell has an independently drawn random perturbation. Moreover, to maintain a set-up similar to the one used in Rains et al. (2017), where air temperature perturbations are propagated to the soil temperature via the CLM model, perturbed soil temperature predictions are here drawn from the perturbed air temperature. This is done in two steps. First, linear regressions are carried out on each grid cell between the ERA-Interim predictions of air temperature and soil temperature (separately for the two soil layers). Next, perturbed soil temperatures are derived from the perturbed air temperatures based on the coefficients obtained from the linear regressions. This allows us to maintain a certain level of consistency between perturbed air and soil temperatures for each ensemble member. The main difference between our experiment and the one of Rains et al. (2017) is that we do not perturb soil texture, as this parameter of CLM does not apply to SFX. Table 2 re- ports the similarities and differences between the two quasiidentical assimilation experiments.

\subsection{Analyses used to evaluate the proposed soil moisture prediction chain}

The proposed modelling framework is evaluated and compared to the one proposed in Rains et al. (2017), using a series of empirical tests as follows:

1. We assess the performance of the calibrated conceptual SFX model by comparing, via the Pearson correlation (referred to as $\rho$ in the remainder), the ubRMSD (Eq. 6) and the mean bias, the simulated and observed SMOS Tb.

2. We compare the SFX-based model performance to the one of the forward CLM model previously introduced in Rains et al. (2017). To do so, we make use of the root mean square deviation (RMSD) and the $\rho$ together with the Taylor diagrams computed based on the comparison between CLM (restrictively SFX) model simulations and observations of $\mathrm{Tb}$ (SMOS observation) and SM (in situ measurements).

3. We assess the effect of the assimilation of SMOS Tb by comparing the open loop and the assimilation simulations of SM with in situ SM measurements via the RMSD, the $\rho$, the ubRMSD, the assimilation efficiency (Eq. 8) and Taylor diagrams, and we analyse the spatial distribution of $\rho$ improvement by mapping the $\rho$ changes between predictions and in situ measurements of soil moisture at each stations.

4. We further evaluate the influence of the assimilation of SMOS observations on the prediction of evapotranspiration by comparing the open loop and the assimilation simulation of evapotranspiration with in situ measurements. This comparison is carried out graphically, via Taylor diagrams and time series plots, and numerically, via the percentage improvement (Eq. 9).

The assimilation efficiency is computed as follows:

$$
\begin{array}{r}
E\left(t_{n}\right)= \begin{cases}\left(1-\frac{\mathrm{SD}_{\mathrm{An}}\left(t_{n}\right)}{\mathrm{SD}_{\mathrm{OL}}\left(t_{n}\right)}\right) \times 100, & \text { if } \mathrm{SD}_{\mathrm{An}} \leq \mathrm{SD}_{\mathrm{OL}} \\
\left(\begin{array}{l}
\mathrm{SD}_{\mathrm{OL}}\left(t_{n}\right) \\
\operatorname{SD}_{\mathrm{An}}\left(t_{n}\right)
\end{array}\right) \times 100, & \text { if } \mathrm{SD}_{\mathrm{An}}>\mathrm{SD}_{\mathrm{OL}}\end{cases} \\
\text { With }\left\{\begin{array}{l}
\operatorname{SD}_{\mathrm{OL}}\left(t_{n}\right)=\sum_{t=t_{n}}^{t_{n+1}-1}\left(\theta_{\mathrm{OL}}(t)-\theta_{\mathrm{Obs}}(t)\right)^{2} \\
\operatorname{SD}_{\mathrm{An}}\left(t_{n}\right)=\sum_{t=t_{n}}^{t_{n+1}-1}\left(\theta_{\mathrm{An}}(t)-\theta_{\mathrm{Obs}}(t)\right)^{2},
\end{array}\right.
\end{array}
$$

where $E\left(t_{n}\right)$ is the efficiency of the analysis at time step $t_{n}$, $\mathrm{SD}_{\mathrm{An}}$ is the squared deviation of the analysis run, $\mathrm{SD}_{\mathrm{OL}}$ is the squared deviation of the open loop run, $\theta_{\mathrm{Obs}}$ is the observed soil moisture, $\theta_{\mathrm{An}}$ is the analysis soil moisture prediction and $\theta_{\mathrm{OL}}$ is the open loop soil moisture prediction. The efficiency evaluates the squared deviation change as a result of the assimilation. Positive values indicate an error reduction, while 
Table 2. Similarities and differences between the two quasi-identical assimilation experiments.

\begin{tabular}{lll}
\hline Experiment characteristics & CLM-based study & SFX-based study \\
\hline Number of root zone soil layers & Five & Two \\
\hline Ensemble generation & $\begin{array}{l}\text { Perturbed input rainfall } \\
\text { Perturbed input air temperature } \\
\text { Perturbed soil texture parameters }\end{array}$ & $\begin{array}{l}\text { Perturbed input rainfall } \\
\text { Perturbed input air temperature } \\
-\end{array}$ \\
\hline Simulation time steps & \multicolumn{2}{c}{ Identical; $1 \mathrm{~h}$} \\
\hline Model grid size & Identical; 0.25 \\
\hline Source of model forcings & Identical; ERA-Interim \\
\hline Radiative transfer model & Identical; CMEM using the same parameterisation \\
\hline Assimilation filter & Identical; LETKF \\
\hline Assimilated satellite observations & Identical; SMOS Tb \\
\hline
\end{tabular}

negative ones indicate that the squared deviation increased after the analysis step.

The percentage improvement is computed as follows:

$$
\begin{aligned}
I(t)= & \frac{\left|E a_{\mathrm{OL}}(t)-E a_{\mathrm{Obs}}(t)\right|-\left|E a_{\mathrm{An}}(t)-E a_{\mathrm{Obs}}(t)\right|}{\left|E a_{\mathrm{OL}}(t)-E a_{\mathrm{Obs}}(t)\right|} \\
& \times 100,
\end{aligned}
$$

where $t$ is the time step, $I$ is the percentage improvement and $E a_{\mathrm{Obs}}, E a_{\mathrm{OL}}$ and $E a_{\mathrm{An}}$, respectively, are the observed, background and analysis evapotranspiration. The positive (restrictively negative) percentage improvement values indicate that absolute errors are reduced (restrictively increased) as a result of the assimilation of SMOS Tb.

\section{Results and discussion}

In this section, the performance of the conceptual SFX model is assessed and compared to the one of the physically based CLM land surface model by comparing the simulated and observed time series of $\mathrm{Tb}$ and soil moisture.

\subsection{Evaluation of the calibrated SFX hydrological model}

Figure 3 shows the $\rho$ coefficient, the RMSD and the mean bias maps obtained by comparing SFX-simulated and SMOS-observed $\mathrm{Tb}$ time series, and Table 3 reports the associated spatial statistics during the calibration (2010-2011) and the validation (2012-2015). The $\mathrm{p}$ values associated to $\rho$ coefficients are all below 0.01 , lending, therefore, weight to the significance of the $\rho$ between simulated Tb and SMOS Tb. From this figure and this table, the following results can be noted:

1. The calibrated model yields rather satisfying predictions of $\mathrm{Tb}$. In addition, the obtained performances are comparable to those obtained in Rains et al. (2017). In particular, in our study we have an average $\rho$ of 0.7 , an average ubRMSD of $14.8 \mathrm{~K}$ and an average bias of $30.21 \mathrm{~K}$ during the validation period. In the study of Rains et al. (2017) using CLM, the RMSD has an average value of $30 \mathrm{~K}$, and the average $\rho$ has a value of 0.7 .

2. The three performance metrics have rather similar values and spatial variability when computed during the calibration and the validation periods, although slight differences are visible in Table 3.

3. A general gradient in the performance of SFX can be seen from the eastern to the western part of the basin, whereas this gradient is not observed in the CLM.

4. The lowest performances are mainly exhibited on pixels located in the Darling River floodplain (Fig. 1).

Results 1 and 2 lead us to conclude that model results are satisfactory in view of previous applications. Result 3 can be explained based on the fact that the hydrological regimes vary from east to west in the MDB. Where the eastern part is more dominated by rainfall, the western part receives limited amounts of rainfall, and evapotranspiration plays a more important role in the hydrological cycle. Considering that in our set-up, the representation of the evapotranspiration is rather simplistic as it is based on the Hamon formula; this could explain the poorer performance of the model in the western part of the basin. Indeed, the simplified representation of the SFX model does not allow us to adequately capture the evapotranspiration-induced controls of soil moisture, which revealed a poorer performance of the model in the western part of the basin. Result 4 can be explained considering the input data used for running CMEM concerning the fraction of the grid cell that is covered by surface water. This input is considered invariant over time in our set-up, while in reality 

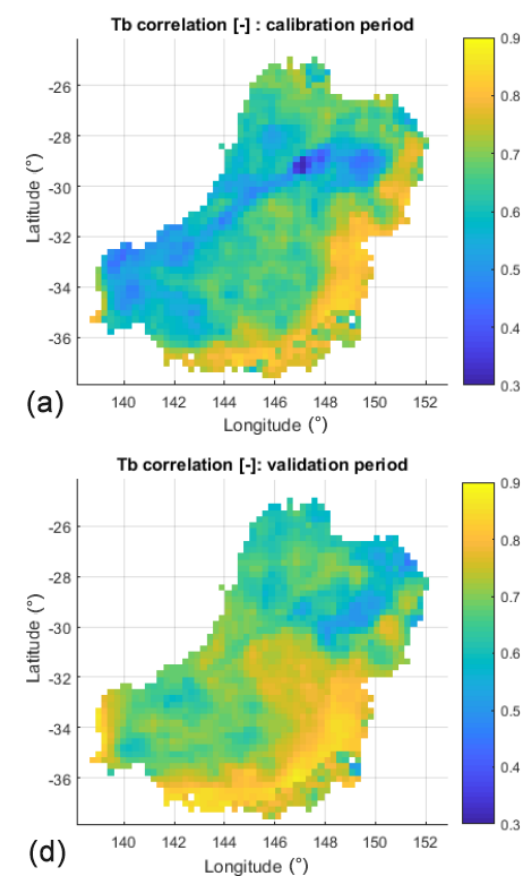
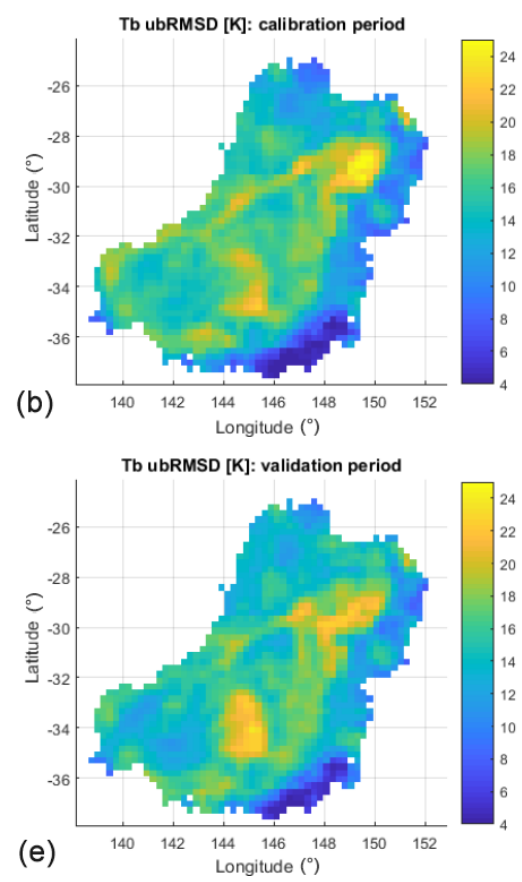
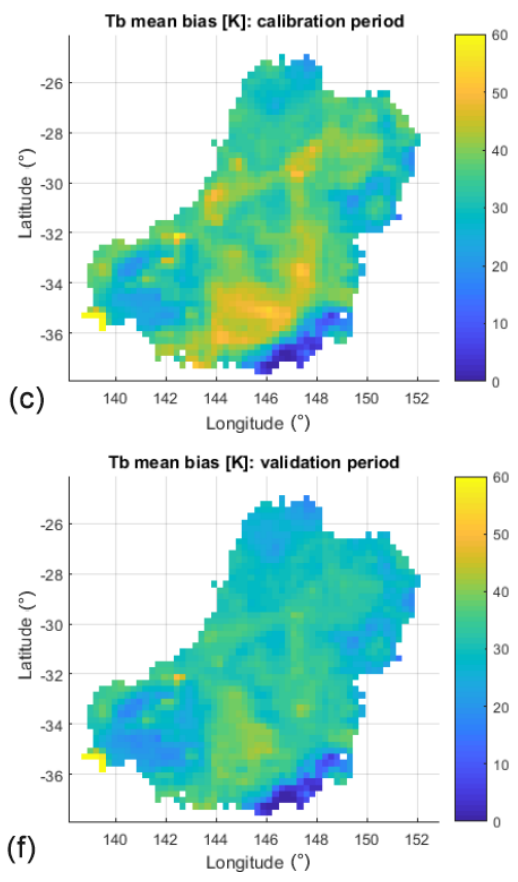

Figure 3. Performance and error metrics of SFX-simulated Tb using, as a reference, SMOS Tb. $\rho$ coefficients (a, d), unbiased root mean square deviations (ubRMSD; b, e) and mean biases (c, f) between SFX-CMEM predictions and SMOS observations of Tb during the calibration (a-c) and the validation (d-f) periods.

an important number of lakes and ponds in the Darling River floodplain are periodically drying out and filling up during the year, potentially modifying the water fraction on the corresponding model grid cells.

\subsection{Comparison of the performances of the SUPERFLEX and CLM models}

To compare the SFX-based model performance to the one of the forward CLM model previously introduced in Rains et al. (2017), we first make use of Taylor diagrams (Fig. 4). These represent useful tools for evaluating and inter-comparing model performances as they display, on a unique plot, three key performance statistics, namely the normalised standard deviation of model results, the RMSD and the $\rho$ between model predictions and observations. The normalisation of the standard deviation and RMSD is carried out with respect to observed time series statistics. The perfect model would therefore be a point located in the black circle in Fig. 4, with values of normalised SD, normalised RMSD and $\rho$ equal to 1,0 and 1 , respectively.

Figure 4 assumes that the SMOS Tb observations are reliable and accurate. Figure 4a shows the spatially averaged model statistics of both models during the calibration and the validation periods. As can be seen, the performances of both models are similar, with average $\rho$ ranging between 0.62 and 0.72 during the calibration and validation periods. Whereas SFX slightly outperforms CLM during the calibration period, CLM exhibits relatively better $\rho$ during the validation pe- riod. Overall, both models yield very similar levels of satisfying performances. The performances obtained here are also rather similar to the ones showed in De Lannoy and Reichle (2016a), with a $\rho$ between in situ observed and simulated SM of 0.6 on average over many stations located in the United States of America. One can notice that both models have a tendency to underestimate the observed variance of $\mathrm{Tb}$ as normalised standard deviation values are lower than one. Our interpretation is that the two models are unable to reproduce the variance of SMOS observations, mainly due to some limitations of the radiative transfer modelling (e.g. inaccurate estimates of surface roughness or vegetation optical depth). Indeed, even with completely dry or wet soils, the simulated $\mathrm{Tb}$ does not reach the extreme values of the SMOS Tb. Figure 4a shows the model performance for each individual model grid cell. The model statistics here are computed over the complete simulation period (calibration and validation periods). At the model grid cell scale, both model statistics cover a rather wide range of performance levels. This highlights the fact that both models, albeit yielding good overall levels of performance, are less accurate for a few cells. Overall, the performance metrics shown in Fig. 4 confirm that the two models reach similar levels of performance.

Figure 5 shows the maps of difference in $\rho$ and RMSD between both models and the map of average hourly rainfall and Ep. Figure 5a highlights a gradient in the $\rho$ values from west to east; the SFX-predicted Tb is better correlated with SMOS observations in the eastern part of the basin, where precipi- 
Table 3. Spatial statistics of simulated Tb performance metrics (computed using SMOS Tb as a reference). Note: Cal - calibration period; Val - validation period.

\begin{tabular}{lrrrrrr}
\hline \multirow{2}{*}{ Performance metric } & \multicolumn{2}{c}{$\rho(-)$} & \multicolumn{3}{c}{$\operatorname{ubRMSD}(\mathrm{K})$} & \multicolumn{2}{c}{ Mean bias (K) } \\
\cline { 2 - 7 } Spatial statistic & Cal & Val & Cal & Val & Cal & Val \\
\hline Mean & 0.65 & 0.70 & 14.75 & 14.8 & 34.70 & 30.21 \\
Median & 0.65 & 0.69 & 15.31 & 14.86 & 35.37 & 31.02 \\
Mode & 0.32 & 0.44 & 3.91 & 4.25 & 0.10 & -1.11 \\
Skewness & -0.14 & -0.08 & -0.61 & -0.40 & -0.01 & 0.75 \\
Kurtosis & 2.78 & 2.78 & 3.67 & 3.98 & 12.06 & 23.54 \\
\hline
\end{tabular}

Tb - spatially averaged statistics

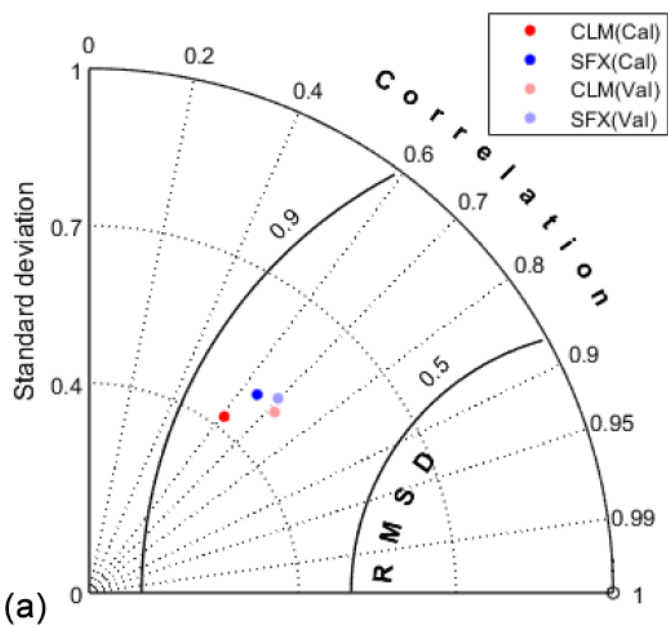

Tb - model grid cells

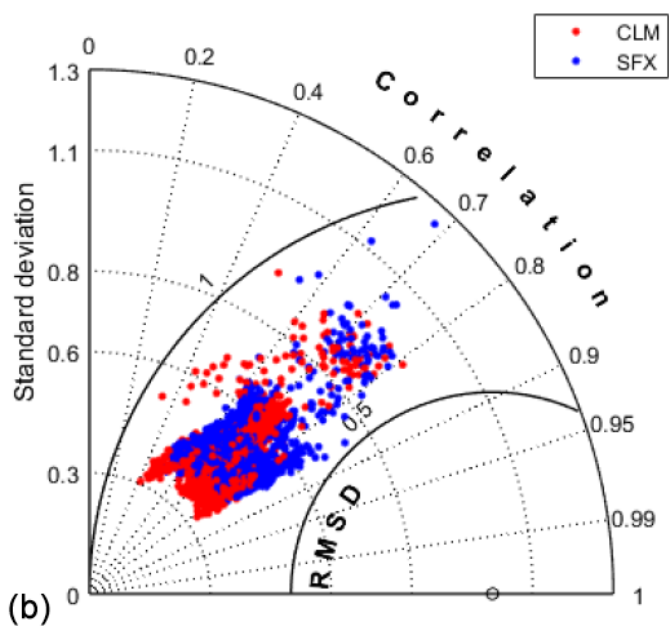

Figure 4. Taylor diagrams (TDs) based on the comparison between SMOS-observed and SFX- and CLM-simulated Tb, respectively. The TD in panel (a) is drawn by spatially averaging model grid cell statistics, separating the calibration (Cal) and validation (Val) periods, and the TD in panel (b) is drawn using model grid cell statistics individually for calibration and validation periods together. Red dots indicate CLM statistics, and blue dots indicate SFX statistics.

tation is mainly controlling soil moisture dynamics (Fig. 5c), and the CLM-predicted Tb is better correlated with SMOS observation in the western part, where evapotranspiration has a higher impact on soil moisture variations (Fig. 5d). This is arguably explained by a better representation of the evapotranspiration process in CLM and a better capability of SFX to simulate fast transfer of rainfall to deeper soil layers at saturation. Figure 5a shows a generally higher deviation in SFX-based predictions of Tb.

As SMOS observations likely suffer from significant uncertainties, we propose evaluating the model results using in situ observed soil moisture time series from a limited number of available measurement sites further (Fig. 1). In this context, Fig. 6 shows the Taylor diagrams drawn from the comparison between the time series of soil moisture observed and simulated by both models for the thin upper soil layer (Fig. 6a) and a deeper soil layer (Fig. 6b). For the thin upper soil layer $(0-8 \mathrm{~cm}$ depth), the observations are directly compared with the soil moisture simulations of the upper SFX reservoir. For the deeper soil layer $(0-30 \mathrm{~cm}$ depth), the ob- servations are compared with the average soil moisture predictions computed as the weighted mean, with the weighting proportional to the maximum storage capacity of the upper and lower SFX reservoirs (see Fig. 2). Both models exhibit similar $\rho$ values. For the upper soil layer, SFX is better in capturing the observation variance. Regarding the RMSD, CLM slightly outperforms SFX with sometimes lower values for the upper soil layer. For the deeper soil layer, both models again yield similar performance levels with satisfying $\rho$ values, with SFX slightly overperforming CLM.

As a conclusion on the comparison between the forward run of both models, it can be highlighted that the two models finally reach similar performance levels when using either observed SMOS Tb or in situ measured soil moisture as a reference. It is also important to keep in mind that similar performance levels have been attained provided that the SFX model was calibrated, whereas CLM was not calibrated using SMOS data. We argue that, while a conceptual model such as SFX requires a calibration effort because its parameter values cannot be set a priori, CLM is not supposed to 

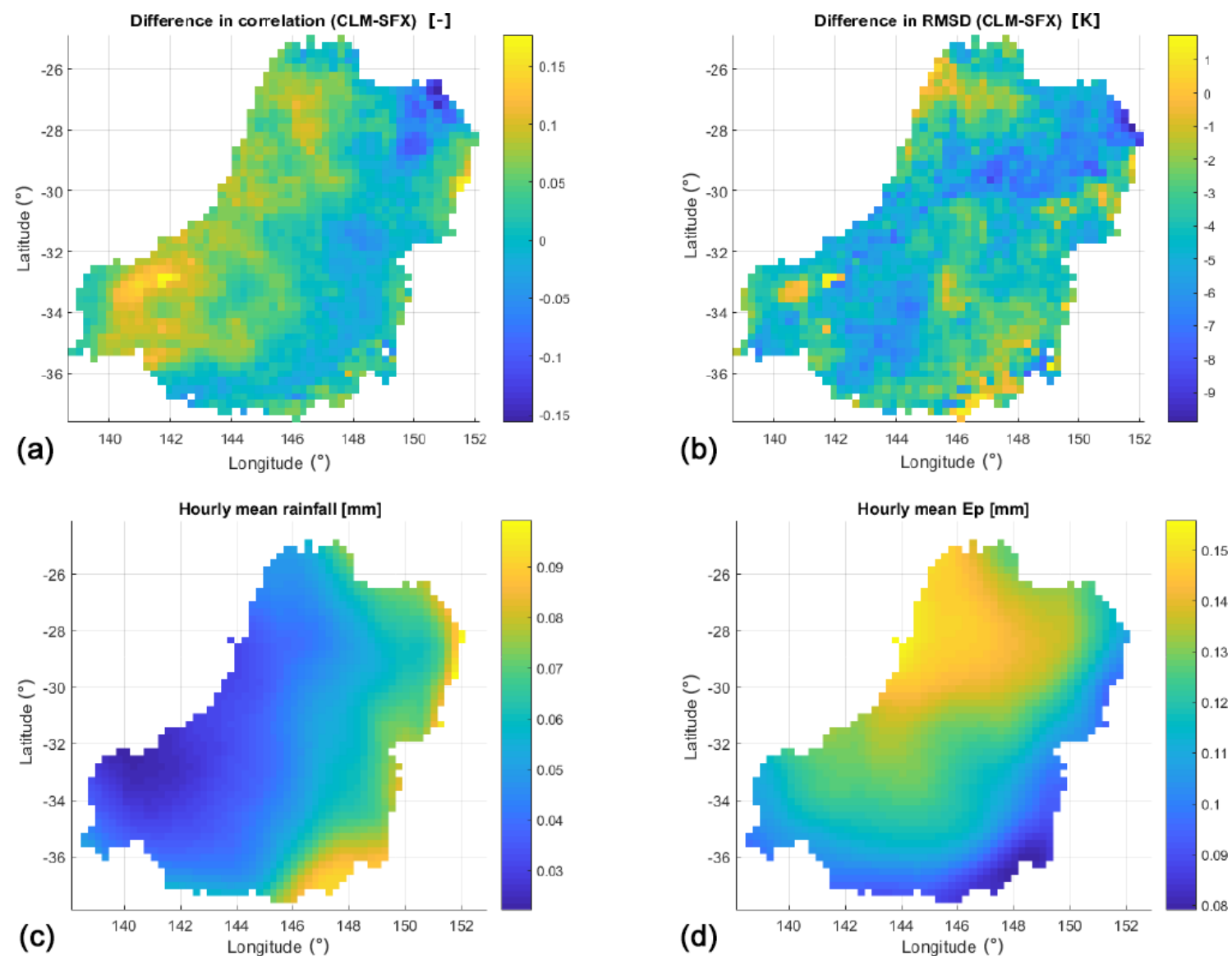

Figure 5. Maps of differences in $\rho$ (a) and RMSD (b) between CLM- and SFX-simulated Tb, using SMOS observation as a reference, and maps of hourly averages of input rainfall (c) and potential evapotranspiration Ep (d).
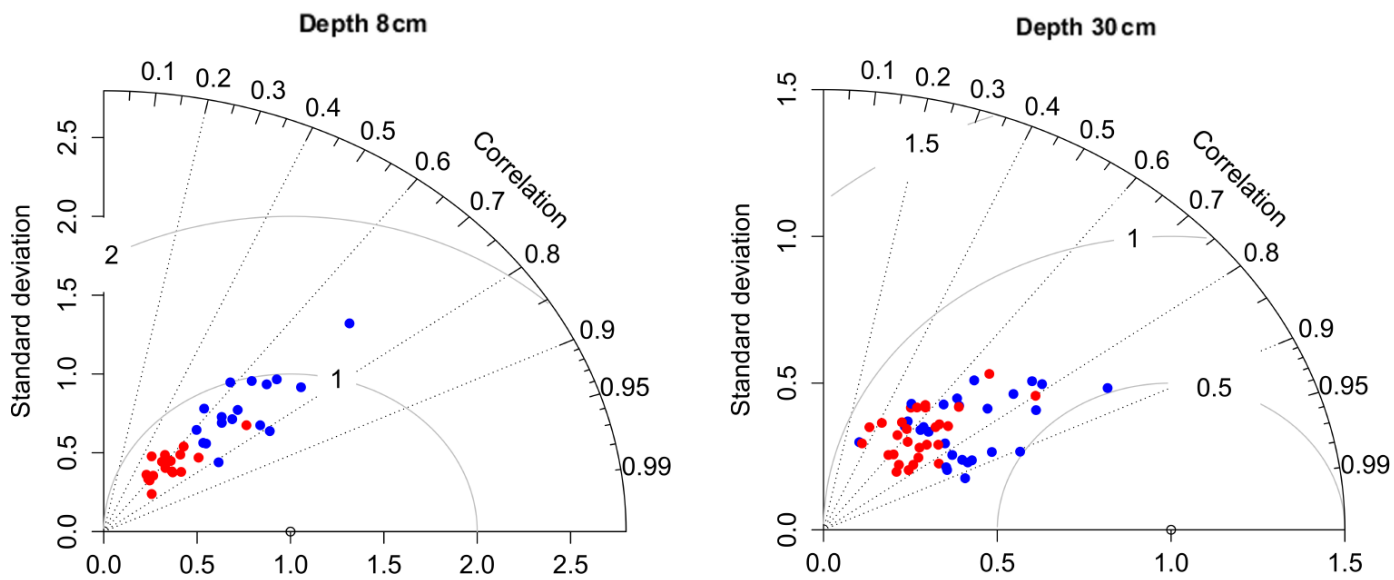

Figure 6. Taylor diagrams (TDs) drawn from the comparison between in situ observed and SFX-simulated soil moisture for two different soil depths and the two different models. Blue dots indicate SFX statistics, and red dots indicate CLM statistics.

be calibrated as it is physically based, and its parameters are usually derived from various input data describing, for example, the characteristics of the catchment (Hou et al., 2012). Moreover, one can argue that, because of a large num- ber of parameters, calibrating CLM using SMOS data would not be an easy task especially due to the computational demand (Karagiannis et al., 2019) over a large basin such as the Murray-Darling. The calibration of many parameters would 
consequently lead to a widely reported equifinality issue. Of course it is worth mentioning here that CLM performs satisfactorily - even without any calibration.

\subsection{Effect of the assimilation of SMOS Tb on the SFX hydrological model}

The data assimilation framework proposed in Sect. 2.3 is applied over the period 2010-2015. Each time a SMOS observation is available over a model grid cell, the assimilation filter is applied on the background, and the soil water storage variables of SFX are updated. We assimilated SMOS anomalies, and in the error covariance of the SMOS observation anomalies $R$ is assumed constant and equal to $25 \mathrm{~K}^{2}$ (as in Rains et al., 2017). Table 4 reports the spatially averaged performance metrics of the open loop (i.e. without assimilation) and the analysis SM simulations for two soil layer depths. As some model grid cells include several soil moisture measurement stations, with the objective of compensating for the limited footprint, the average performance metrics in Table 4 are computed both over the individual soil moisture measurement stations and over the cells where in situ observations are available. In the second case, all soil moisture observations available in a given model grid cell are first averaged. The performance metrics are next computed, using the "averaged" observations as a reference. Eventually, the average metrics are obtained by spatially averaging the model gridcell-based metrics. As can be seen in Table 4, the assimilation allows for a moderate increase in $\rho$ for the two soil layers depicted in the model when comparing observed and simulated soil moisture time series. Specifically, the $\rho$ increases, on average, by more than 0.03 for both soil layer depths. These improvements are similar, although slightly lower than those obtained in the study by Rains et al. (2017, experiments DA2 and DA0), namely ca. 0.06 for upper layers and 0.03 for deeper layers. One possible explanation for the slightly lower improvements in $\rho$ for the top layer can be found in the SFX open loop performance already being higher $(\rho=0.77)$ than that of CLM $(\rho=0.61)$. This arguably limits the room for improvement as a result of the assimilation, as the SFX-based open loop outperforms the one based on CLM. Moreover, the fact that the SFX model was calibrated using SMOS Tb and forced using the ERA-Interim data set can also explain the fact that the improvement in the soil moisture predictions are slightly lower than in other studies relying on uncalibrated land surface models (e.g. Rains et al., 2017; De Lannoy and Reichle, 2016a).

To assess the significance of the $\rho$ improvement as a result of the assimilation, we carried out Williams' significance tests (Williams, 1959). The null hypothesis in this test is that the $\rho$ improvement is not significant. For the upper soil layer the $\mathrm{p}$ values are lower than 0.01 , except for two stations where $\rho$ remains almost constant. For the deeper soil layer the $\mathrm{p}$ values are lower than 0.01 , except for three stations where $\rho$ remains almost constant or slightly decreased.
This shows that the $\rho$ increase, as a result of the assimilation of SMOS Tb, can arguably be considered significant for the large majority of stations.

However, while $\rho$ values increase due to the positive effect of the assimilation, one can notice in Table 4 that errors (RMSD and ubRMSD) tend to remain rather stable. This indicates that the assimilation improves $\rho$ between model predictions and observations but fails to reduce average errors in our experiment. This result is consistent with the findings of Rains et al. (2017).

To evaluate the effect of the assimilation on individual measurement points, Fig. 7 shows the Taylor diagrams obtained from the comparison between model predictions and in situ observations of soil moisture for two soil layer depths. In this figure, the circles indicate the open loop run performances, and the triangles indicate the assimilation run performances. Each colour is assigned to an individual observation point. In Fig. 7 almost every individual observation point exhibits a $\rho$ improvement due to the assimilation, and this is for both soil layers. More precisely, all $\rho$ values increase for the first layer, and all $\rho$ values, except one, increase for the second soil layer. The improvement is, however, rather different from one point measurement to another. Moreover, Fig. 7 indicates that, in general, the lower the open loop run $\rho$, the higher the improvement. This general feature is especially visible for the deeper soil layer.

To analyse the spatial distribution of $\rho$ improvement as a result of the SMOS data assimilation, Fig. 8 maps the $\rho$ changes between the predictions and in situ measurements of soil moisture at all stations and the temporal average of assimilation SM increments (Fig. 8a-b), together with the average annual rainfall and Ep, and the number of SMOS records assimilated over in situ soil moisture measurement sites (Fig. 8c-d). Figure 8a and b show local $\rho$ improvements and SM increments in the 8 and $30 \mathrm{~cm}$ top soil layer, respectively. Figure $8 \mathrm{c}-\mathrm{d}$ show the climate variability over the Murrumbidgee catchment using, as a proxy, the average annual rainfall and Ep (data provided by the Australian Bureau of Meteorology) together with the number of SMOS records assimilated over in situ soil moisture measurement sites. In Fig. 8c, the same colour scale is used to indicate the rainfall amount (map) and the number of SMOS observations assimilated at each measurement station (colour of each point). The number of stations differs between Fig. 8a and $\mathrm{b}$ as all stations do not measure soil moisture for all soil depths. Figure 8c-d indicate all measurement stations. Especially for the first layer, one can notice a gradient from east to west within the Murrumbidgee basin (where observation sites are located). Figure 8c-d indicate that it is likely that the gradient in $\rho$ increase has its origin in climate variability, but that it also depends on the number of SMOS observations that are locally assimilated (Fig. 8c). In the western semi-arid Murrumbidgee, soil moisture updates tend to have a longer lasting effect on the performance because evapotranspiration is the main soil-moisture-controlling process and because the 
Table 4. Time-space average values of background and analysis performance (comparison with in situ observed soil moisture).

\begin{tabular}{lrlrrr}
\hline Space averaging & Layer depth & & $\rho$ & RMSD & ubRMSD \\
\hline Over measurement stations & $8 \mathrm{~cm}$ & Open loop & 0.776 & 0.1 & 0.98 \\
\cline { 3 - 6 } & & Analysis & 0.801 & 0.1 & 0.98 \\
\cline { 3 - 6 } & $30 \mathrm{~cm}$ & Open loop & 0.695 & 0.11 & 0.071 \\
\cline { 3 - 6 } & & Analysis & 0.727 & 0.11 & 0.072 \\
\hline \multirow{2}{*}{ Over model grid cells } & $8 \mathrm{~cm}$ & Open loop & 0.771 & 0.1 & 0.099 \\
\cline { 3 - 6 } & & Analysis & 0.803 & 0.1 & 0.1 \\
\cline { 3 - 6 } & \multirow{2}{*}{$30 \mathrm{~cm}$} & Background & 0.695 & 0.11 & 0.062 \\
\cline { 3 - 6 } & & Analysis & 0.726 & 0.11 & 0.064 \\
\hline
\end{tabular}

Depth $8 \mathrm{~cm}$

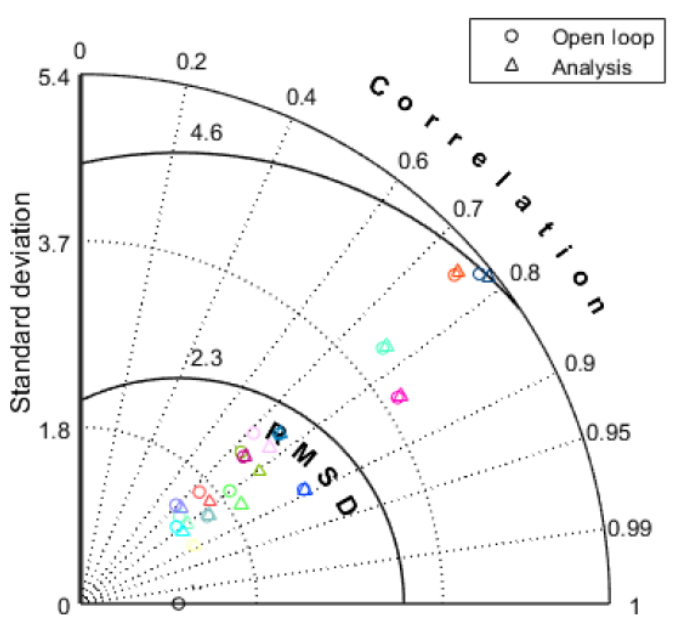

Depth $30 \mathrm{~cm}$

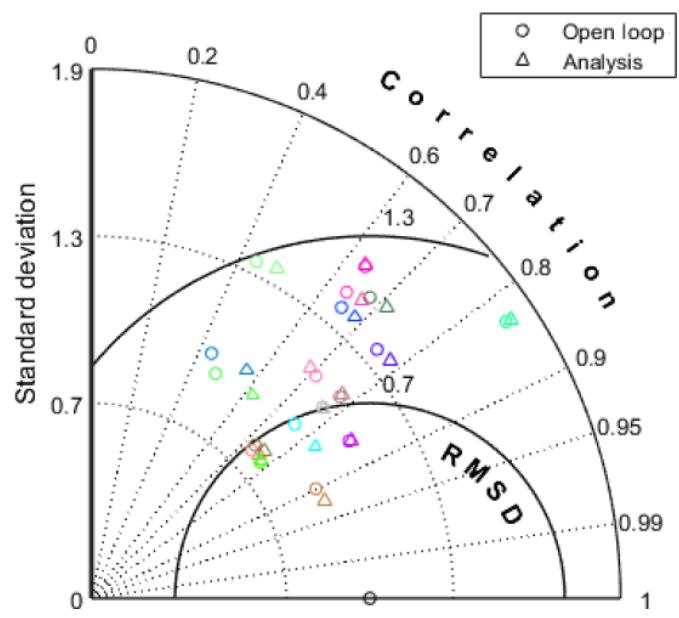

Figure 7. Taylor diagrams (TDs) drawn from the comparison between in situ observed and SFX-simulated (background and analysis) soil moisture for the two different soil depths.

extraction of water from the soil due to evapotranspiration takes much longer than soil recharge due to rainfall. Moreover, one can notice in Fig. 8a-b that $\rho$ improvements are higher in areas where the temporal average of the absolute SM increments are higher and vice versa. This indicates that the $\rho$ is further improved when absolute SM increments tend to be higher.

Overall, our experiment shows that the assimilation of SMOS data into the SFX model allows for a substantial improvement in the $\rho$ between model predictions and in situ observations of soil moisture, with improvements similar to those obtained in a very similar study by Rains et al. (2017) using the CLM land surface model.

In Fig. 9, we plot the averaged efficiency as a function of the open loop soil moisture prediction percentiles for two soil depths to further investigate the effect of the assimilation on soil moisture prediction errors. To do so, we first compute, for each individual efficiency, the percentile of the synchronously obtained open loop soil moisture prediction, and then we compute the average efficiency for each percentile of the open loop soil moisture predictions. Figure 9 shows that the errors in soil moisture prediction are mainly reduced by the assimilation for the higher quantiles of soil moisture, while they tend to increase for the lower quantiles. For the upper layer, the assimilation is more efficient for predicted soil moisture values higher than the median. For the deeper layer, errors are reduced for quantiles higher than $80 \%$. This indicates that the assimilation is more efficient for high soil moisture states. A possible explanation for this is that the assimilation reduces errors when the upper soil layers are closer to saturation, mainly during rainfall events when errors in ERA-Interim rainfall simulations are arguably affected by larger errors. Although there is no absolute evidence that errors are larger for larger rainfall events for the Murray-Darling basin, this is something that was often re- 


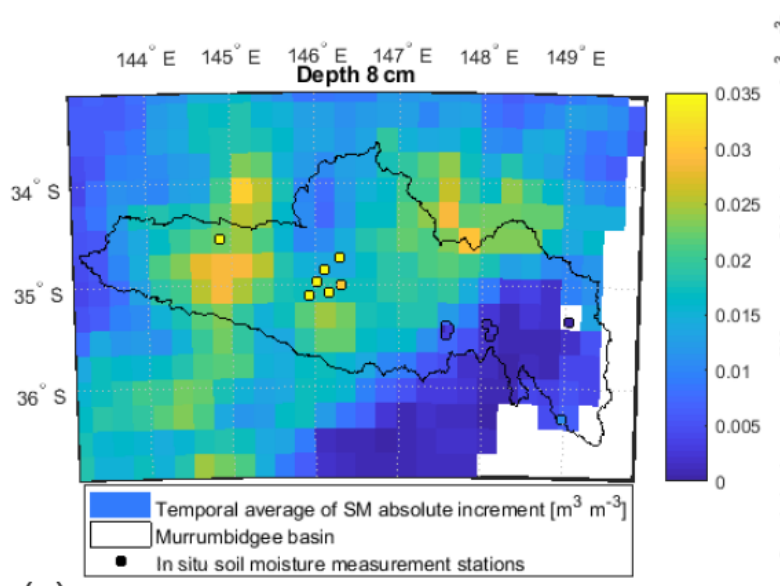

(a)

$144^{\circ} \mathrm{E} \quad 145^{\circ} \mathrm{E} \quad 146^{\circ} \mathrm{E} \quad 147^{\circ} \mathrm{E} \quad 148^{\circ} \mathrm{E} \quad 149^{\circ} \mathrm{E}$

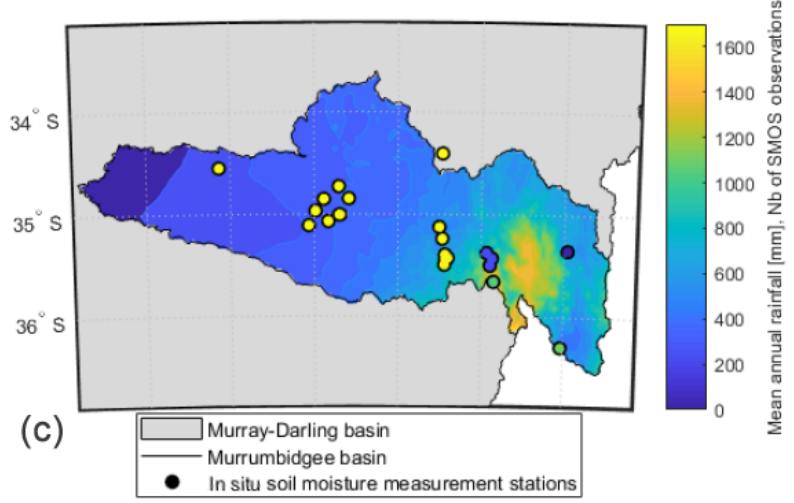

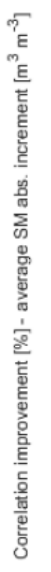

(b)

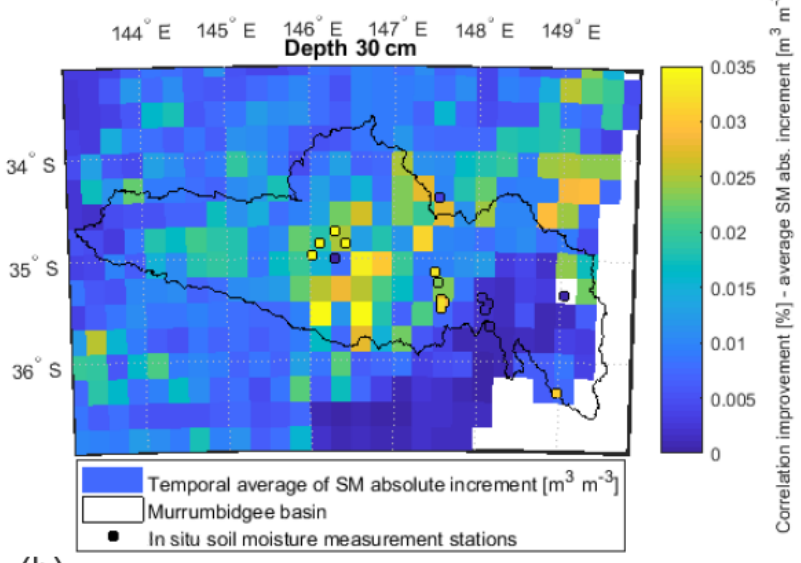

$144^{\circ} \mathrm{E} \quad 145^{\circ} \mathrm{E} \quad 146^{\circ} \mathrm{E} \quad 147^{\circ} \mathrm{E} \quad 148^{\circ} \mathrm{E} \quad 149^{\circ} \mathrm{E}$

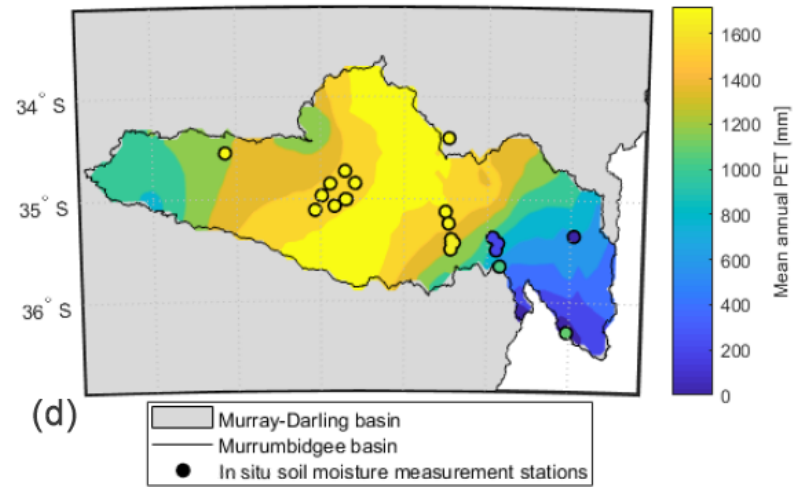

Figure 8. Correlation improvement in soil moisture prediction in relation to assimilation absolute increment, climate variability and number of assimilation events. (a, b) Maps of the improvement in soil moisture $\rho$ and of the time average of absolute assimilation soil moisture (SM) increments for the two root zone soil layers, and maps of the number of assimilated SMOS Tb observations at each soil moisture measurement station (indicated via the dot colours) in relation to the interannual average rainfall map (c) and interannual average Ep map (d). Note: $\mathrm{Nb}$ - number.

ported (for different areas of interest) in the literature as, for example, in the study by $\mathrm{Xu}$ et al. (2019).

\subsection{Effect of the assimilation on predicted evapotranspiration}

As evapotranspiration is also an important control in soil moisture dynamics, we propose evaluating the influence of the assimilation of SMOS observations on the monthly prediction of evapotranspiration further. To do so, we compared the open loop and analysis simulations of monthly evapotranspiration with in situ observations derived from the flux towers (TERN OzFlux measurement network; http://www. ozflux.org.au/). Evapotranspiration observations are derived from monthly averaged flux tower measurements of latent heat flux. The comparison between observations and simulation results is carried out on the grid cells, including the flux towers. The spatially averaged performance metrics yielded by this comparison are reported in Table 5, which reveals that the predictions of evapotranspiration are improved by
Table 5. Time-space average values of background and analysis performances of evapotranspiration predictions (comparison with in situ observed evapotranspiration).

\begin{tabular}{lrrr}
\hline & $\begin{array}{r}\rho \\
(-)\end{array}$ & $\begin{array}{r}\text { RMSD } \\
\left(\mathrm{mmh}^{-1}\right)\end{array}$ & $\begin{array}{r}\text { ubRMSD } \\
\left(\mathrm{mmh}^{-1}\right)\end{array}$ \\
\hline Background & 0.46 & 0.057 & 0.034 \\
Analysis & 0.48 & 0.056 & 0.034 \\
\hline
\end{tabular}

the assimilation of SMOS observations as the $\rho$ with in situ observations increased by 0.02 , with a marginal reduction in RMSD. To assess the significance of the $\rho$ improvement as a result of the assimilation, we carried out Williams' significance tests (Williams, 1959). The corresponding $\mathrm{p}$ values are all lower than 0.01 , except for one station where the $\rho$ slightly decreases, indicating that the $\rho$ increase as a result of the assimilation of SMOS Tb can arguably be considered significant for most of the stations. 

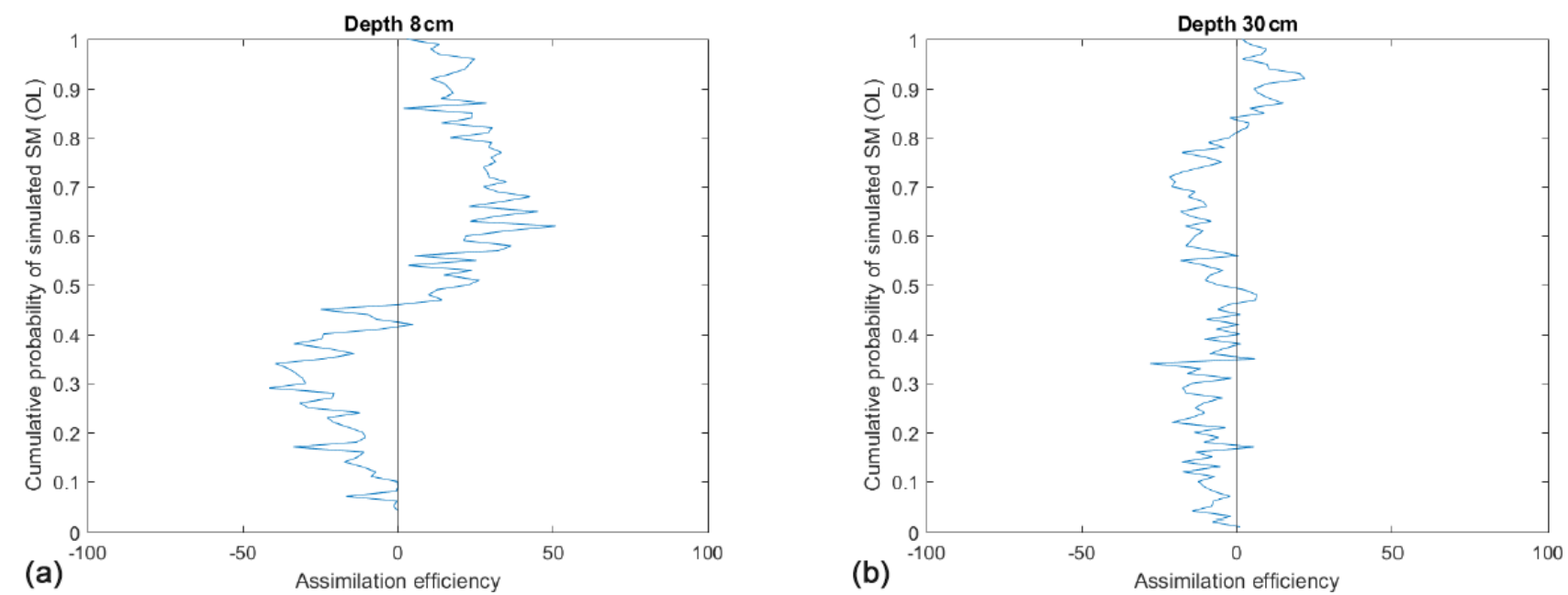

Figure 9. Assimilation efficiency as a function of simulated soil moisture quantiles, namely the upper soil layer (a) and deeper soil layer (b).
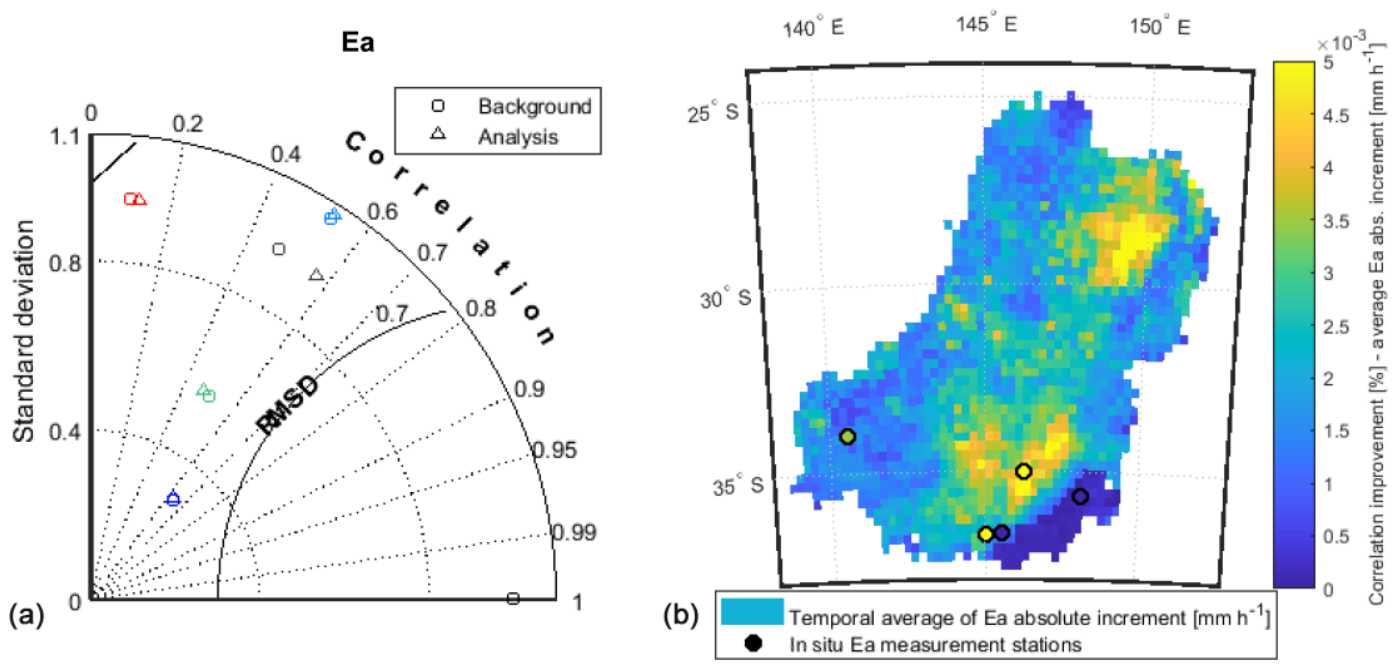

Figure 10. Effect of the assimilation on simulated evapotranspiration. Taylor diagram drawn from the comparison between in situ observed and SFX-simulated evapotranspiration (background and analysis $-\mathbf{a}$ ), and map of the $\rho$ improvement and time average of absolute increments in evapotranspiration (b).

Figure 10 shows a Taylor diagram and a map of $\rho$ improvement for individual measurement stations and the temporal average of evapotranspiration increments. The effect of the assimilation on evapotranspiration is substantially positive for one station, limited for three of them and slightly negative for the last one. As for SM, one can notice in Fig. 10a that the $\rho$ is further improved when absolute evapotranspiration increments tend to be higher. Figure 11 shows the percentage improvement in simulated monthly evapotranspiration as a results of SMOS Tb for each individual flux tower measurement together with averaged monthly rainfall (simulated by ERA-Interim).

In Fig. 11, the assimilation leads, from time to time, either to an increase in or a reduction in the error in simulated evapotranspiration. While the site with low annual pre- cipitation (ca. $250 \mathrm{~mm} \mathrm{yr}^{-1}$ at Calperum) exhibited a quasisystematic improvement, sites with medium annual precipitation (between ca. 480 to $560 \mathrm{~mm} \mathrm{yr}^{-1}$ at Whroo, Riggs and Yanco) exhibited more contrasting results. The wettest site (ca. $720 \mathrm{~mm} \mathrm{yr}^{-1}$ at Tumbarumba) showed a very limited effect of the assimilation on the absolute error in simulated evapotranspiration. This result is in agreement with other studies (e.g. Detto et al., 2006; Vivoni et al., 2008; Mallick et al., 2018) that showed that water limitations in arid and semi-arid regions make evapotranspiration very sensitive to soil moisture variations, thereby explaining the fact that the assimilation of SMOS Tb is more efficient in reducing errors of simulated evapotranspiration in water-limited regions of the MDB. 

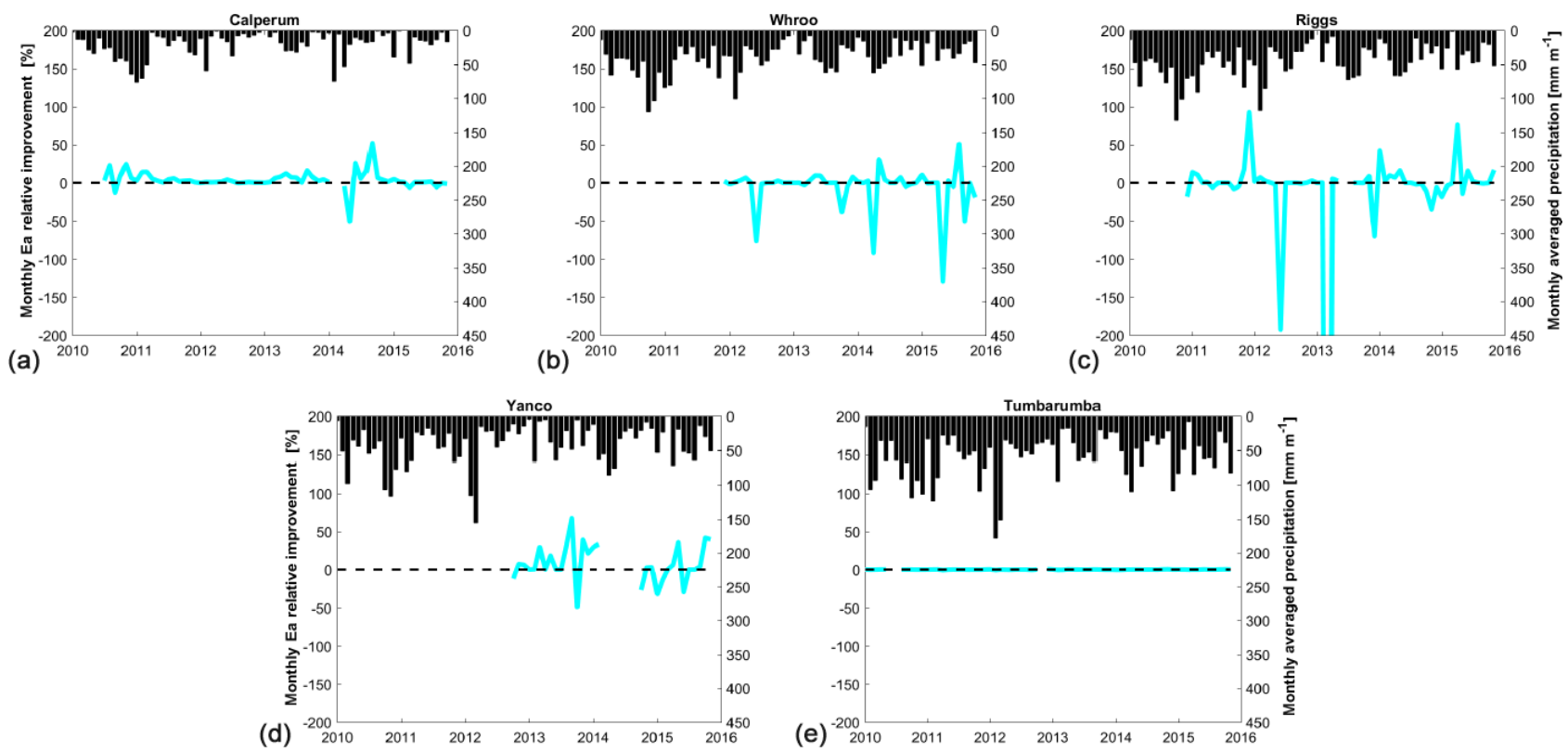

Figure 11. Effect of the assimilation on simulated evapotranspiration. Monthly rainfall and percentage improvement of simulated monthly evapotranspiration as a result of SMOS Tb assimilation for each individual flux tower measurement. Flux tower locations are sorted from west (a) to east (e).

\section{Conclusions}

This study introduced and evaluated a large-scale SM modelling chain that is based on and takes advantage of the assimilation of SMOS Tb into a spatially distributed conceptual hydrological model coupled with a radiative transfer model. We assessed the performance of such a modelling chain and its associated data assimilation system and compared it with that of a quasi-identical set-up using the physically based CLM land surface model (Rains et al., 2017). We evaluated, therefore, whether a SM modelling chain, based on a conceptual hydrological model, is able to reach the same performance level as that of one based on a physically based model, with the main advantage of a conceptual model being its substantially lower computational demand. Eventually, we also evaluated how the assimilation of SMOS Tb can help to improve evapotranspiration predictions.

The following key conclusions can be drawn from our experiment:

1. A 6 year forward run of the SFX-based modelling chain reaches performance levels similar to those obtained with CLM both in terms of simulated Tb (comparison with SMOS data) and SM (comparison with in situ observations). The average $\rho$ values between simulated and observed SMOS Tb range between 0.62 and 0.72 for both models. The local $\rho$ values between simulated and in situ observed SM range between 0.3 and 0.8 for CLM and between 0.3 and 0.9 for SFX.
2. The assimilation of SMOS Tb observations into the SFX-based modelling chain increases the correlation between simulated and in situ observed SM by ca. 0.03 .

3. The improvement in correlation between simulated and in situ observed SM as a result of the assimilation is slightly lower in our study than that obtained in Rains et al. (2017), but the correlation values are higher. As a result of the assimilation, the average correlations between simulated and in situ observed SM (top and deeper root zone soil layers) range between 0.65 and 0.68 for CLM and between 0.73 and 0.8 for SFX.

4. The assimilation of SMOS Tb observations reduces errors between simulated and in situ observed SM, especially for the highest SM values, while it tends to increase them for lower SM values. For the upper layer, errors are reduced for SM values higher than the median. For the deeper layer, errors are reduced for quantiles higher than $80 \%$.

5. The assimilation of SMOS Tb observations increases the correlation by 0.02 and marginally reduces errors between simulated and in situ observed evapotranspiration.

Overall, the study provides consistent empirical evidence that the SM modelling chain based on a conceptual hydrological model can reach, and at times exceed, the performance levels of a modelling chain based on a more physically based state-of-the-art land surface model. While our assimilation experiment with SFX was carried out on a personal computer 
within a few hours, a high-performance computing cluster (using two nodes of 12 cores) was necessary to run the Rains et al. (2017) experiment over a few days. This shows the added value of a computationally efficient conceptual model, especially for applications where computational time is critical. Although the conceptual model needs to be calibrated, our experiment shows that this calibration can be carried out using only satellite data and therefore has the potential to be applicable to all areas in which satellite data are reliable and informative.

Code availability. The code of the version of the SFX model used in this study can be obtained from the corresponding author upon request.

Author contributions. RH wrote the paper with support from all coauthors. All of the authors contributed to the design of the experiment and the analysis of the results. RH implemented the codes necessary for the experiments. DR provided the data sets and contributed to the comparison between the SFX- and the CLM-based experiments.

Competing interests. The authors declare that they have no conflict of interest.

Financial support. The research reported herein was funded by the Luxembourg National Research Fund and the Belgian Federal Science Policy Office (BELSPO) through the HYDRAS+ (grant nos. SR/8888433 and SR/00/302) and the CASCADE (grant no. $\mathrm{C} 17 / \mathrm{SR} / 11682050)$ projects.

Review statement. This paper was edited by Harrie-Jan Hendricks Franssen and reviewed by three anonymous referees.

\section{References}

Al Bitar, A., Leroux, D., Kerr, Y. H., Merlin, O., Richaume, P., Sahoo, A., and Wood, E. F.: Evaluation of SMOS Soil Moisture Products Over Continental U.S. Using the SCAN/SNOTEL Network, IEEE T. Geosci. Remote, 50, 1572-1586, 2012.

Al-Yaari, A., Wigneron, J.-P., Kerr, Y., Rodriguez-Fernandez, N., O’Neill, P., Jackson, T., Lannoy, G. D., Bitar, A. A., Mialon, A., Richaume, P., Walker, J., Mahmoodi, A., and Yueh, S.: Evaluating soil moisture retrievals from ESA's SMOS and NASA's SMAP brightness temperature datasets, Remote Sens. Environ., 193, 257-273, 2017.

Andreadis, K. and Schumann, G.-P.: Estimating the impact of satellite observations on the predictability of large-scale hydraulic models, Adv. Water Resour., 73, 44-54, 2014.
Bergström, S.: Development and application of a conceptual runoff model for Scandinavian catchments, SMHI Report RHO 7, Norrköping, Tech. rep., SMHI, 1976.

Brocca, L., Melone, F., Moramarco, T., Wagner, W., Naeimi, V., Bartalis, Z., and Hasenauer, S.: Improving runoff prediction through the assimilation of the ASCAT soil moisture product, Hydrol. Earth Syst. Sci., 14, 1881-1893, https://doi.org/10.5194/hess-14-1881-2010, 2010.

Brocca, L., Moramarco, T., Melone, F., Wagner, W., Hasenauer, S., and Hahn, S.: Assimilation of surface-and root-zone ASCAT soil moisture products into rainfall-runoff modeling, IEEE T. Geosci. Remote, 50, 2542-2555, 2012.

Champeaux, J. L., Masson, V., and Chauvin, F.: ECOCLIMAP: a global database of land surface parameters at $1 \mathrm{~km}$ resolution, Meteorol. Appl., 12, 29-32, 2005.

Chen, F., Crow, W. T., and Ryu, D.: Dual forcing and state correction via soil moisture assimilation for improved rainfall-runoff modeling, J. Hydrometeorol., 15, 1832-1848, 2014.

Choudhury, B., Schmugge, T. J., Chang, A., , and Newton, R.: Effect of surface roughness on the microwave emission from soils, J. Geophys. Res.-Oceans, 84, 5699-5706, 1979.

Dee, D., Uppala, S., Simmons, A., Berrisford, P., Poli, P., Kobayashi, S., Andrae, U., Balmaseda, M., Balsamo, G., Bauer, P., Bechtold, P., Beljaars, A., van de Berg, L., Bidlot, J., Bormann, N., Delsol, C., Dragani, R., Fuentes, M., Geer, A., Haimberger, L., Healy, S., Hersbach, H., Hólm, E., Isaksen, L., Kållberg, P., Köhler, M., Matricardi, M., McNally, A., Monge-Sanz, B., Morcrette, J.-J., Park, B.-K., Peubey, C., de Rosnay, P., Tavolato, C., Thépaut, J.-N., and Vitart, F.: The ERA-Interim reanalysis: configuration and performance of the data assimilation system, Q. J. R. Meteorol. Soc., 137, 553-597, 2011.

De Lannoy, G. and Reichle, R.: Assimilation of SMOS brightness temperatures or soil moisture retrievals into a land surface model, Hydrol. Earth Syst. Sci., 20, 4895-4911, 2016a.

De Lannoy, G. J. M. and Reichle, R. H.: Global assimilation of multiangle and multipolarization SMOS brightness temperature observations into the GEOS-5 Catchment Land Surface Model for soil moisture estimation, J. Hydrometeorol., 17, 669-691, $2016 \mathrm{~b}$.

De Lannoy, G. J. M., Reichle, R. H., Houser, P. R., Pauwels, V., and Verhoest, N. E.: Correcting for forecast bias in soil moisture assimilation with the ensemble Kalman filter, Water Resour. Res., 43, W09410, https://doi.org/10.1029/2006WR005449, 2007.

de Rosnay, P., Drusch, M., Boone, A., Balsamo, G., Decharme, B., Harris, P., Kerr, Y., Pellarin, T., Polcher, J., and Wigneron, J.-P.: AMMA Land Surface Model Intercomparison Experiment coupled to the Community Microwave Emission Model: ALMIP-MEM, J. Geophys. Res.-Atmos., 114, D05108, https://doi.org/10.1029/2008JD010724, 2009.

Detto, M., Montaldo, N., Albertson, J. D. Mancini, M., and Katul, G.: Soil moisture and vegetation controls on evapotranspiration in a heterogeneous Mediterranean ecosystem on Sardinia, Italy, Water Resour. Res., 42, W08419, https://doi.org/10.1029/2005WR004693, 2006.

Devia, G., Ganasri, B., and Dwarakish, G.: A review on hydrological models, Aquat. Proc., 4, 1001-1007, 2015.

Dharssi, I., Bovis, K. J., Macpherson, B., and Jones, C. P.: Operational assimilation of ASCAT surface soil wetness at the Met Office, Hydrol. Earth Syst. Sci., 15, 2729-2746, https://doi.org/10.5194/hess-15-2729-2011, 2011. 
Draper, C., Mahfouf, J.-F., and Walker, J.: An EKF assimilation of AMSR-E soil moisture into the ISBA land surface scheme, J. Geophys. Res.-Atmos., 114, D20104, https://doi.org/10.1029/2008JD011650, 2009.

Draper, C., Mahfouf, J.-F., Calvet, J.-C., Martin, E., and Wagner, W.: Assimilation of ASCAT near-surface soil moisture into the SIM hydrological model over France, Hydrol. Earth Syst. Sci., 15, 3829-3841, https://doi.org/10.5194/hess-15-3829-2011, 2011.

Draper, C. S., Reichle, R. H., De Lannoy, G. J. M., and Liu, Q.: Assimilation of passive and active microwave soil moisture retrievals, Geophys. Res. Lett., 39, L04401, https://doi.org/10.1029/2011GL050655, 2012.

El Hassan, A. A., Sharif, H. O., Jackson, T., and Chintalapudi, S.: Performance of a conceptual and physically based model in simulating the response of a semi-urbanized watershed in San Antonio, Texas, Hydrol. Process., 27, https://doi.org/10.1002/hyp.9443, 2013.

Entekhabi, D., Reichle, R. H., Koster, R. D., and Crow, W. T.: Performance Metrics for Soil Moisture Retrievals and Application Requirements, J. Hydrometeorol., 11, 832-840, 2010.

Ercolani, G. and Castelli, F.: Real-time variational assimilation of hydrologic and hydrometeorological data into operational hydrologic forecasting, Water Resour. Res., 53, 158-183, 2017.

Fenicia, F., Kavetski, D., and Savenije, H.: Elements of a flexible approach for conceptual hydrological modeling: 1. Motivation and theoretical development, Water Resour. Res., 47, W11510, https://doi.org/10.1029/2010WR010174, 2011.

Fenicia, F., Kavetski, D., Savenije, H. H. G., and Pfister, L.: From spatially variable streamflow to distributed hydrological models: Analysis of key modeling decisions, Water Resour. Res., 52, 954-989, 2016.

García-Pintado, J., Mason, D. C., Dance, S. L., Cloke, H. L., Neal, J. C., Freer, J., and Bates, P. D.: Satellite-supported flood forecasting in river networks: A real case study, J. Hydrol., 523, 706724, 2015.

Hamon, W.: Computation of direct runoff amounts from storm rainfall, IAHS-AISH P, 63, 52-62, 1963.

Holgate, C., De Jeu, R., van Dijk, A., Liu, Y., Renzullo, L., Vinodkumar, Dharssi, I., Parinussa, R., Schalie, R. V. D., Gevaert, A., Walker, J., McJannet, D., Cleverly, J., Haverd, V., Trudinger, C., and Briggs, P.: Comparison of remotely sensed and modelled soil moisture data sets across Australia, Remote Sens. Environ., 186, 479-500, 2016.

Hostache, R., Matgen, P., Montanari, A., Montanari, M., Hoffmann, L., and Pfister, L.: Propagation of uncertainties in coupled hydrometeorological forecasting systems: A stochastic approach for the assessment of the total predictive uncertainty, Atmos. Res., 100, 263-274, 2011.

Hostache, R., Matgen, P., Giustarini, L., Teferle, F., Tailliez, C., Iffly, J.-F., and Corato, G.: A drifting GPS buoy for retrieving effective riverbed bathymetry, J. Hydrol., 520, 397-406, 2015.

Hostache, R., Chini, M., Giustarini, L., Neal, J., Kavetski, D., Wood, M., Corato, G., Pelich, R.-M., and Matgen, P.: Near-RealTime Assimilation of SAR-Derived Flood Maps for Improving Flood Forecasts, Water Resour. Res., 54, 5516-5535, 2018.

Hou, Z., Huang, M., Leung, L. R., Lin, G., and Ricciuto, D. M.: Sensitivity of surface flux simulations to hydrologic parameters based on an uncertainty quantification framework applied to the Community Land Model, J. Geophys. Res.-Atmos., 117, https://doi.org/10.1029/2012JD017521, 2012.

Hunt, B. R., Kostelich, E. J., and Szunyogh, I.: Efficient data assimilation for spatiotemporal chaos: A local ensemble transform Kalman filter, Phys. D, 230, 112-126, 2007.

Jia, B., Xie, Z., Tian, X., and Shi, C.: A soil moisture assimilation scheme based on the ensemble Kalman filter using microwave brightness temperature, Sci. China Ser. D, 52, 1835-1848, 2009.

Karagiannis, G., Hou, Z., Huang, M., and Lin, G. P.: Inverse modeling of hydrologic parameters in CLM4 via generalized polynomial chaos in the Bayesian framework, arXiv: Applications, arXiv:1910.08409, 2019.

Kerr, Y. H., Waldteufel, P., Wigneron, J. P., Martinuzzi, J., Font, J., and Berger, M.: Soil moisture retrieval from space: the Soil Moisture and Ocean Salinity (SMOS) mission, IEEE T. Geosci. Remote, 39, 1729-1735, 2001.

Kerr, Y. H., Waldteufel, P., Richaume, P., Wigneron, J. P., Ferrazzoli, P., Mahmoodi, A., Bitar, A. A., Cabot, F., Gruhier, C., Juglea, S. E., Leroux, D., Mialon, A., and Delwart, S.: The SMOS Soil Moisture Retrieval Algorithm, IEEE T. Geosci. Remote, 50, 1384-1403, 2012.

Lehner, B., Döll, P., Alcamo, J., Henrichs, T., and Kaspar, F.: Estimating the impact of global change on flood and drought risks in Europe: A continental integrated analysis, Clim. Change, 75, 273-299, 2016.

Liang, X., Lettenmaier, D. P. andWood, E. F., and Burges, S. J.: A simple hydrologically based model of land surface water and energy fluxes for general circulation models, J. Geophys. Res., 99, 14415-14428, 1994.

Lievens, H., De Lannoy, G., Al Bitar, A., Drusch, M., Dumedah, G., Hendricks Franssen, H.-J., Kerr, Y., Tomer, S., Martens, B., Merlin, O., Pan, M., Roundy, J., Vereecken, H., Walker, J., Wood, E., Verhoest, N., and Pauwels, V.: Assimilation of SMOS soil moisture and brightness temperature products into a land surface model, Remote Sens. Environ., 180, 292-304, 2016.

Liu, Y. and Gupta, H. V.: Uncertainty in hydrologic modeling: Toward an integrated data assimilation framework, Water Resour. Res., 43, 1-18, W07401, 2007.

Lü, H., Crow, W., Zhu, Y., Ouyang, F., and Su, J.: Auto-calibration system developed to assimilate AMSR-E data into a land surface model for estimating soil moisture and the surface energy budget, Remote Sens., 8, 1-20, 2016.

Mallick, K., Toivonen, E., Trebs, I., Boegh, E., Cleverly, J., Eamus, D., Koivusalo, H., Drewry, D., Arndt, S., Griebel, A., Beringer, J., and Garcia, M.: Bridging thermal infrared sensing and physically-based evapotranspiration modeling: From theoretical implementation to validation across an aridity gradient in Australian ecosystems, Water Resour. Res., 54, 3409-3435, 2018.

Matgen, P., Fenicia, F., Heitz, S., Plaza, D., de Keyser, R., Pauwels, V., Wagner, W., and Savenije, H.: Can ASCAT-derived soil wetness indices reduce predictive uncertainty in well-gauged areas? A comparison with in situ observed soil moisture in an assimilation application, Adv. Water Resour., 44, 49-65, 2012.

MDBA, T.: http://www.mdba.gov.au, last access: 9 October 2018.

Mironov, V. L., Dobson, M. C., Kaupp, V. H., Komarov, S. A., and Kleshchenko, V. N.: Generalized refractive mixing dielectric model for moist soils, IEEE Trans. Geosci. Remote Sens., 42, 773-785, 2004. 
Miyoshi, T. and Yamane, S.: Local Ensemble Transform Kalman Filtering with an AGCM at a T159/L48 Resolution, Mon. Weather Rev., 135, 3841-3861, 2007.

Mohanty, B. P., Cosh, M. H., Lakshmi, V., and Montzka, C.: Soil Moisture Remote Sensing: State-of-the-Science, Vadose Zone J., 16, 1-9, 2017.

Moradkhani, H.: Hydrologic Remote Sensing and Land Surface Data Assimilation, Sensors, 8, 2986-3004, 2007.

Muñoz-Sabater, J., Lawrence, H., Albergel, C., Rosnay, P., Isaksen, L., Mecklenburg, S., Kerr, Y., and Drusch, M.: Assimilation of SMOS brightness temperatures in the ECMWF Integrated Forecasting System, Q. J. Roy. Meteorol. Soc., 145, 2524-2548, 2019.

Oleson, K. W., Lawrence, D. M., Bonan, G. B., Drewniak, B., Huang, M., Koven, C. D., Levis, S., Li, F., Riley, W. J., Subin, Z. M., Swenson, S. C., and Thornton, P. E.: Technical Description of version 4.5 of the Community Land Model (CLM), Tech. rep., NCAR, Boulder, CO, USA, 2013.

Pappenberger, F., Frodsham, K., Beven, K., Romanowicz, R., and Matgen, P.: Fuzzy set approach to calibrating distributed flood inundation models using remote sensing observations, Hydrol. Earth Syst. Sci., 11, 739-752, https://doi.org/10.5194/hess-11739-2007, 2007.

Parada, L. M. and Liang, X.: Optimal multiscale Kalman filter for assimilation of near-surface soil moisture into land surface models, J. Geophys. Res.-Atmos., 109, D24109, https://doi.org/10.1029/2004JD004745, 2004.

Peischl, S., Walker, J. P., Rüdiger, C., Ye, N., Kerr, Y. H., Kim, E., Bandara, R., and Allahmoradi, M.: The AACES field experiments: SMOS calibration and validation across the Murrumbidgee River catchment, Hydrol. Earth Syst. Sci., 16, 16971708, https://doi.org/10.5194/hess-16-1697-2012, 2012.

Pellarin, T., Wigneron, J. P., Calvet, J. C., Berger, M., Douville, H., Ferrazzoli, P., Kerr, Y. H., Lopez-Baeza, E., Pulliainen, J., Simmonds, L. P., and andWaldteufel, P.: Two-year global simulation of L-band brightness temperatures over land,, IEEE Trans. Geosci. Remote Sens., 41, 2135-2139, 2003.

Perrin, C., Michel, C., and Andréassian, V.: Improvement of a parsimonious model for streamflow simulation, J. Hydrol., 279, 275289, 2003.

Rains, D., Han, X., Lievens, H., Montzka, C., and Verhoest, N. E. C.: SMOS brightness temperature assimilation into the Community Land Model, Hydrol. Earth Syst. Sci., 21, 5929-5951, https://doi.org/10.5194/hess-21-5929-2017, 2017.

Rains, D., De Lannoy, G. J. M., Lievens, H., Walker, J. P., and Verhoest, N. E. C.: SMOS and SMAP Brightness Temperature Assimilation Over the Murrumbidgee Basin, IEEE T. Geosci. Remote, 15, 1652-1656, 2018.

Reichle, R. H., Koster, R. D., Liu, P., Mahanama, S. P., Njoku, E. G., and Owe, M.: Comparison and assimilation of global soil moisture retrievals from the Advanced Microwave Scanning Radiometer for the Earth Observing System (AMSR-E) and the Scanning Multichannel Microwave Radiometer (SMMR), J. Geophys. Res.-Atmos., 112, D09108, https://doi.org/10.1029/2006JD008033, 2007.

Renzullo, L. J., Van Dijk, A., Perraud, J.-M., Collins, D., Henderson, B., Jin, H., Smith, A., and McJannet, D.: Continental satellite soil moisture data assimilation improves root-zone moisture analysis for water resources assessment, J. Hydrol., 519, $2747-$ 2762, 2014.

Revilla-Romero, B., Wanders, N., Burek, P., Salamon, P., and de Roo, A.: Integrating remotely sensed surface water extent into continental scale hydrology, J. Hydrol. B, 543, 659-670, 2016.

Smith, A. B., Walker, J. P., Western, A. W., Young, R. I., Ellett, K. M., Pipunic, R. C., Grayson, R. B., Siriwidena, L., Chiew, F. H. S., and Richter, H.: The Murrumbidgee Soil Moisture Monitoring Network Data Set, Water Resour. Res., 48, W07701, https://doi.org/10.1029/2012WR011976, 2012.

Su, C.-H., Ryu, D., Young, R. I., Western, A. W., and Wagner, W. Inter-comparison of microwave satellite soil moisture retrievals over the Murrumbidgee Basin, southeast Australia, Remote Sens. Environ., 134, 1-11, 2013a.

Su, Z., de Rosnay, P., Wen, J., Wang, L., and Zeng, Y.: Evaluation of ECMWF's soil moisture analyses using observations on the Tibetan Plateau, J. Geophys. Res.-Atmos., 118, 5304-5318, 2013b.

UNISDR: Sendaï Framework for Disaster Risk Reduction 20152030, Tech. rep., United Nations Office for Disaster Risk Reduction, Sendai, Japan, 2015.

Vivoni, E. R., Moreno, H. A., Mascaro, G., Rodriguez, J. C., Watts, C. J., Garatuza-Payan, J., and Scott, R. L.: Observed relation between evapotranspiration and soil moisture in the North American monsoon region hydrologic forecasting, Geophys. Res. Lett., 35, L22403, https://doi.org/10.1029/2008GL036001, 2008.

Wanders, N., Karssenberg, D., de Roo, A., de Jong, S. M., and Bierkens, M. F. P.: The suitability of remotely sensed soil moisture for improving operational flood forecasting, Hydrol. Earth Syst. Sci., 18, 2343-2357, https://doi.org/10.5194/hess-18-23432014, 2014.

Wigneron, J.-P., Laguerre, L., and Kerr, Y. H.: A simple parameterization of the L-band microwave emission from rough agricultural soils, IEEE Trans. Geosci. Remote Sens., 39, 1697-1707, 2001.

Wigneron, J.-P., Kerr, Y., Waldteufel, P., Saleh, K., Escorihuela, M.J., Richaume, P., Ferrazzoli, P., De Rosnay, P., Gurney, R., Calvet, J.-C., Grant, J. P., Guglielmetti, M., Hornbuckle, B., Mätzler, C., Pellarin, T., and Schwank, M.: L-band microwave emission of the biosphere (L-MEB) model: Description and calibration against experimental data sets over crop fields, Remote Sens. Environ., 107, 639-655, 2007.

Williams, E.: The Comparison of Regression Variables, J. Roy. Stat. Soc.-Ser. B, 21, 396-399, 1959.

Wood, M., Hostache, R., Neal, J., Wagener, T., Giustarini, L., Chini, M., Corato, G., Matgen, P., and Bates, P.: Calibration of channel depth and friction parameters in the LISFLOOD-FP hydraulic model using medium-resolution SAR data and identifiability techniques, Hydrol. Earth Syst. Sci., 20, 4983-4997, https://doi.org/10.5194/hess-20-4983-2016, 2016.

Xu, X., Frey, S. K., Boluwade, A., Erler, A. R., Khader, O., Lapen, D. R., and Sudicky, E.: Evaluation of variability among different precipitation products in the Northern Great Plains, J. Hydrol.-Reg. Stud., 24, 100608, https://doi.org/10.1016/j.ejrh.2019.100608, 2019.

Yang, K., Watanabe, T., Koike, T., Li, X., Fujii, H., Tamagawa, K., Ma, Y., and Ishikawa, H.: Auto-calibration system developed to assimilate AMSR-E data into a land surface model for estimating soil moisture and the surface energy budget, J. Meteorol. Soc. Jpn. Ser. II, 85, 229-242, 2007. 